\title{
An experimental investigation of resilience decision making in repeated disasters
}

\author{
Noah C. Dormady ${ }^{1}$ (D) $\cdot$ Robert T. Greenbaum $^{1}$ (D) $\cdot$ Kim A. Young $^{1}$ (D) \\ Accepted: 20 May 2021 / Published online: 7 June 2021 \\ (c) The Author(s), under exclusive licence to Springer Science+Business Media, LLC, part of Springer Nature 2021
}

\begin{abstract}
Given the growing prevalence of catastrophic events and health epidemics, policymakers are increasingly searching for effective strategies to encourage firms to invest in resilience rather than relying on insurance or government assistance. Too often, however, resilience research focuses on decisions made by firms and emergency planners in the context of "one-off" events. We extend this research by examining resilience decision making in the more realistic context of repeated catastrophic events. Using a population of professional managers of middle market firms and a university experimental economics subject pool, we conduct a series of controlled experiments on the decision to invest in inventories to improve firm resilience to repeated catastrophic events. While existing economic and supply chain resilience research has focused on resilience in terms of avoiding some magnitude of economic losses, existing research omits a focus on the probability of those losses. Controlled experiments can evaluate the influence of probability more effectively than observational data by better controlling for magnitude and more easily accounting for repeated events. We find that decision makers are less likely to make resilience investments when a disaster has recently occurred. We further find that advisory information alone is insufficient to motivate resilience investments by firms. It must be substantiated by a history of advisory accuracy. However, we find that this effect is heavily moderated by the type of advisory information provided; we find that firm managers are much more likely to trust precautionary advice.
\end{abstract}

Keywords Resilience $\cdot$ Experimental economics $\cdot$ Inventories $\cdot$ Natural hazards $\cdot$ Emergency management $\cdot$ Middle market

$\mathrm{JEL} \mathrm{C92} \cdot \mathrm{C} 25 \cdot \mathrm{E} 22 \cdot \mathrm{G} 31 \cdot \mathrm{H} 54 \cdot \mathrm{Q} 54$

\section{Introduction}

The specter of both human-induced and natural disasters has led to a great deal of planning for low probability and high damage events. In the midst of the COVID-19 global pandemic, it is a particularly appropriate time to examine the factors that affect decision makers' willingness to follow precautionary advice. Experience with previous epidemics shows that one of the important factors in convincing people to heed such advice is the credibility of the source (Van Bavel et al. 2020). Often, however, literature examining the preparation for these potentially large disruptions treats them as one-off events and ignores that decision makers likely

Robert T. Greenbaum

greenbaum.3@osu.edu

1 John Glenn College of Public Affairs, The Ohio State University, Columbus, OH, USA update their assessments of the risk of future disasters based explicitly or implicitly upon the occurrence, or lack of occurrence, of past disasters. An important and often overlooked part of an economy's resilience to such disasters is the business continuity decisions individual businesses make to build resilience capacity. Our research addresses this considerable gap in the literature by evaluating individual-level resilience decisions and their determinants in the context of repeated disaster events.

The effectiveness of any policy aimed at increasing business or organizational resilience to disasters will partially be a function of how business leaders assess threats and are willing to act on advice to sacrifice current profits to protect against potential future losses due to catastrophic events. When making such cost-benefit calculations, even if decision makers have a strong sense of the potential losses due to disruptions in their business operations, the nature of most catastrophic events is such that the probability of a 
disruption in a finite period is typically unknown. Decision makers likely update initial risk probability assessments over time in response to whether and how often such events occur. Furthermore, business leaders rarely make important investment recommendations such as these without input from others. This type of advice, and, in particular, the perceived accuracy and trustworthiness of the advice, also likely play a role in driving these investment decisions.

While research addressing individual decision making has focused on how individual attributes affect risk perception or risk preference, we instead draw on prospect theory (Kahneman and Tversky 1979) to attempt to examine the extent to which the decisions to invest in resilience in the context of repeated events are influenced by factors such as confirmatory bias, recency bias, and the law of small numbers. These human tendencies can lead to vexing strategic investment challenges. For example, if a region experiences a "500-year flood," how does one convince decision makers that this does not absolve them of preparing for similar future disasters? This is not just an academic exercise, as Houston faced so-called 500-year-floods in 2016 and then again in 2017 with Hurricane Harvey (Popovich and O'Neill 2017).

Thus, while we expect cumulative repeated exposure to disasters leads decision makers to be more likely to invest in resilience as decision makers reassess risk probabilities, prospect theory leads us to expect a lower probability of resilience investment immediately subsequent to a disaster. Further, we expect advice provided to the decision makers to influence their decisions, particularly when experience show the advice to be accurate or when the advice is more consistent with the decision maker's underlying beliefs.

To examine the resilience decision making of firms in the context of repeated catastrophic events, we conduct a series of controlled experiments on the decision to invest in inventories to improve firm resilience. An investment in inventories is a well-known and common firm- or household-level resilience tactic (Rose and Liao 2005; Dormady et al. 2019a, b). We use a sample of both professional managers of middle market firms and a university experimental economics subject pool. The use of a controlled experiment represents an important advancement to existing resilience literature that relies on field data, as such data cannot be used to disentangle the effect of a first disaster on investment decisions in the same way. It is important to note that while controlled experiments are often employed to test tenets of prospect theory, our goal is instead to draw upon prospect theory while using our experiment to help shed additional light on how policy can help support resilience- enhancing decisions.

Next, we define resilience and then review some of the literature examining the factors that affect individual resilience-enhancing investments. This paper contributes to the standard conceptualization of resilience by incorporating the probabilistic aspect of resilience and incorporating this into the context of repeated disasters. We provide a detailed description of our controlled experiment that models decision making in the context of the repeated events followed by results. While we do not find that cumulative exposure to more disasters affects resilience decision making, we do find that a recent disaster leads decision makers to be less likely to make resilience investments. While this is consistent with expected behavior via prospect theory, it may also represent a significant challenge for investment planning. Importantly, we find that advisory information does strongly influence resilience investment decisions and can help moderate some of the biases identified in prospect theory. The accuracy of that advisory information further amplifies this effect. Taken as a whole, the results suggest an important role for public sector leaders in fostering economic and supply chain resilience, as well as the resilience of the broader communities and economies that rely upon firms.

\section{Background}

\subsection{Defining resilience}

Resilience has gained increasing attention across multiple domains-from business and management sciences (Tang and Tomlin 2008; Hosseini and Barker 2016; Kamalahmadi and Parast 2016; Brusset and Teller 2017; Chowdhury and Quaddus 2017) to engineering (Hollnagel et al. 2006; Youn et al. 2011; Shafieezadeh and Burden 2014; Hynes, et al. 2020); from ecology (Carpenter et al. 2001; Kerkhoff and Enquist 2007; Webb 2007) to economics (Rose 2004; Rose and Liao 2005; Martin and Sunley 2014); and from sociology (Cacioppo et al. 2011; White et al. 2014; Tierney 2019) to geography (Cutter et al. 2008; Miles and Chang 2011; Martin 2018). Across each of these disparate domains, numerous definitional distinctions have been offered, with domain-specific nuance applied to each. Comparing across these multiple domains, Rose $(2009,2017)$ has generally found more commonalities than differences, and Naderpajouh et al. (2018) call for a more interdisciplinary approach to managing resilience. Despite the commonalities, domainspecific nuance can often preclude research advancement, necessitating an explicit definition of resilience at the outset.

As the intent of this research is not to make a definitional contribution, but rather to advance a generalized decisionmaking experiment that informs how human decision makers process and conceptualize resilience in the context of repeated disasters, we adopt the more generalized definition of resilience advanced by the National Research Council [NRC] (2012) that is "the ability to prepare and plan for, absorb, recover from, or more successfully adapt to actual or 
potential adverse events" (p. 16). ${ }^{1}$ Because experiments like this one are generalizations of external contexts intended to introduce experimental control where observational data cannot present such control, introducing high levels of definitional nuance to human subjects in an experiment would confuse subjects and could heavily bias results. Given this intent toward a generalized application, however, two important conceptual nuances must be addressed, which we turn to next. The first involves the nature of repeated events and temporal dynamics. The second involves considerations specific to the unit of analysis-in this case, the firm.

\subsection{Addressing conceptual distinctions in repeated events}

Addressing the nature of repeated events requires two important time-related dimensions that affect the way in which resilience is conceptualized. The first involves the distinction between static versus dynamic resilience (see e.g., Rose 2004, 2007, 2017). The former involves the manner in which remaining resources are utilized to maintain function when shocked and comports more closely with Holling's (1973) general definition. The latter involves the efficient use of resources over time and comports more with Pimm's (1984) definition. While the application of inventory investments in repeated disasters involves core elements of both concepts, repeated events resilience decisions inherently involve the act of setting aside currently profitable resources in the here and now to maintain function and reestablish productivity in the future. As such, repeated events decisions inherently involve temporal tradeoffs between current opportunity costs and future losses avoided.

Those avoided losses are typically assessed in terms of business interruption, or BI, as measured by sales revenue (see, e.g., Rose and Liao 2005; Dormady et al. 2019a, b). This raises another important distinction, magnitude versus probability. Avoided BI losses are inherently a magnitude consideration, as they measure the size of the loss that was avoided. However, while the opportunity cost of setting aside currently profitable capital or materials in the here and now is certain, the magnitude of the future avoided loss is uncertain and subject to some probability domain. With the exception of Azadegan and Jayaram (2018), who introduce the concept of "anticipative" resilience, we are aware of no existing empirical economic resilience research that has addressed resilience actions that result from information about the probability of the shock in the context of repeated disasters. Additionally, even Azadegan and Jayaram's work does not address this, as anticipative resilience

\footnotetext{
${ }^{1}$ For more nuance on the National Research Council definition, see Connelly et al. (2017).
}

is more consistent with actions taken to build slack capacity in anticipation of a future disaster. So, even their insightful work omits the process of informing the likelihood of a disaster over time in the context of repeated events. It is this dimension, in particular that presents an important motivation for the current experiment. Observational data, as opposed to experiments, cannot hold disaster magnitude constant and vary the disaster frequency in the way that a controlled experiment can.

\subsection{Addressing firm-level decision making in resilience research}

The second important conceptual nuance involves resilience decision-making considerations specific to the unit of analysis. Much of the economic resilience literature has addressed large-scale regional or national-level economic issues such as COVID-19, outages in bulk power systems, and municipal water contamination, to name a few. While some of the research in this area has helped create frameworks for evaluating vulnerability and disaster response (Gerber 2007; Chang, McDaniels, Fox, Dhariwal, and Longstaff 2014; Alderson, Brown, and Matthew 2015; Kim and Marcouiller 2015), others have concentrated on quantifying post-disaster losses, deriving methods of measuring resilience costs, or establishing benchmarks for resilience performance measures (Cimellaro et al. 2010; Park et al. 2011; Vugrin et al. 2011; Henry and Ramirez-Marquez 2016). These types of studies have concentrated on community or regional resilience by examining specific geographic areas (e.g., metro areas or watersheds), organizations (e.g., hospitals), institutions (e.g., public policies), or infrastructure systems (e.g., supply chains, power, and communication networks). While these contributions are important, the microfoundations (i.e., the level of the firm) are noticeably absent.

Scholars who have attempted to quantify the effects of catastrophic events on businesses have largely ignored the attempts by decision makers within firms to minimize potential losses. These types of decisions that originate with an individual decision maker or collaboration among individuals collectively constitute the economic resilience of firms and, ultimately, communities. This gap becomes even more consequential when considering research that shows that individual characteristics and risk attitudes influence corporate policies (e.g., Cronqvis 2012; Roussanov and Savor 2014; Bernile et al. 2017).

While the economic resilience literature has focused on regional or community resilience, much of the existing risk and individual decision-making literature has considered the influence of personal characteristics. For instance, one line of research published in the economic and personal finance literature has examined gender differences in risk preference and has yielded inconsistent findings (Schubert et al. 1999; 
Sonfield et al. 2001; Atkinsonet al. 2003; Beckmann and Menkoff 2008; Eckel and Grossman 2008; Charness and Gneezy 2012; Booth and Katic 2013; Filippin and Crosetto 2016; Sila et al. 2016).

\subsection{Decision making in the context of repeated events}

When faced with making decisions on behalf of the firm, an important individual characteristic that likely influences risk perception is the decision maker's personal experience. Experience with fatal disasters early in life has been shown to predict chief executive officer's (CEO) risk attitudes (Bernile et al. 2017). CEOs born in counties that experienced a moderate number of natural disaster fatalities engaged in more corporate risk-taking behavior than those exposed to low fatalities. However, CEOs born in counties with more extreme disasters pursued less risky corporate activities (Bernile et al. 2017). While Bernile et al. (2017) find a relationship between disaster exposure as a child and subsequent firm-related investments later in life, this research can only hint at the impact of repeated events on decision making.

Hertwig et al. (2004) posited that people with experience likely underweight the likelihood of rare events but overweight them if making decisions from a description of the scenario. They attribute this to the nature of rare events. Given that the events happen only infrequently, people ratchet down their expectations over time, especially because people often overweight the impact of recent events. On the other hand, Yechiam et al. (2005) also hypothesized that experience reduces sensitivity to rare events, but they attributed this to reduced sensitivity of risk. When examining the effect of the Intifada on overnight stays in Israeli hotels, they found that the rise in terrorism led to a much larger reduction in hotel stays by international rather than domestic tourists. Using a laboratory experiment to test their hypothesis regarding the role of personal experience, they found results consistent with their hypothesis that personal experience by the local residents reduced the sensitivity to the risk. Notably, the experiment's participants in the experience treatment tended to revert to risky choices soon after experiencing negative outcomes.

Prospect theory can also shed light on decision making in the context of repeated events. Because perceptions of risk are often a function of drawing from a small, unrepresentative sample. Recency bias leads individuals to overweight their most recent experiences and experiencing an event may lead to underweighting the probability of its reoccurrence (Tversky and Kahneman 1971). This "gambler's fallacy" would lead one to believe that because of the incorrect belief that the small sample represents the large sample of a variable from the same distribution, the occurrence of the rare event would somehow make it less likely to occur in the next period. This is consistent with findings from the literature (e.g., Bell and Tobin 2007) that people are confused by terms like " 100 -year" flood when risk probabilities are presented to them. On the other hand, He and Hong (2018) found in a lottery laboratory experiment that subjects who were exposed to riskier environments in earlier rounds of the experiment displayed greater risk aversion in later rounds of the experiment.

Individuals' own biases can further be reinforced or tempered by advice they seek out or are offered. For instance, a decision maker's willingness to take precautionary measures in the face of risk is also likely to be partially a function of the level of trust in warning advice provided (LeClerc and Joslyn 2015). Confirmation bias, which leads people to overweight evidence conforming to their own initial beliefs, might lead the decision makers to place greater trust in advice consistent with their priors. Further, Slovic (1999) points out that trust is asymmetric in that it is more easily destroyed than created. One explanation is that events that betray trust are typically more perceptible than events that reinforce trust. Interestingly, people are more likely to view sources of bad news as credible but discount sources of good news. Also, distrust, once established, is difficult to overcome.

\subsection{Hypotheses}

To summarize, the insights and gaps in the existing empirical and theoretical research reviewed above lead to the following hypotheses. First, following Bernile et al. (2017), we hypothesize that decision makers who are exposed to a greater number of cumulative disasters will invest in resilience at a higher rate. Second, prospect theory concepts of recency bias and gambler's fallacy imply that decision makers will be less likely to invest in resilience after a disaster has recently occurred. Finally, it is expected that the advice provided regarding resilience investments will influence those investments accordingly; that advice consistent with underlying beliefs will be weighted more, and that, over time, the influence of advice will be qualified by the decision maker's experience with the accuracy of that advice.

We turn next to a discussion of the experimental design to evaluate these hypotheses.

\section{Experimental design}

We utilize a controlled experiment to study the effect of resilience investment recommendations on resilience decisions in the context of repeated catastrophic events. Use of controlled experiments has grown rapidly because of their strengths in testing social phenomena in a structured manner 
(Plott and Smith 2008; Kagel and Roth 2015) and in setting up scenarios in large samples that would not be possible with observational data. Controlled experiments, by their very nature, rank highly in internal validity (Roth, 1995; Roe and Just 2009). However, their external validity regarding generalizability to external policy contexts depends heavily on the choice of assumptions.

Below, we describe the experimental design and rationale. Section 3.1 describes the sampling approach and subject populations, sample size, and the overall operation. Section 3.2 describes the decision-making scenario along with the payment structure. Section 3.3 describes design considerations relating to the dynamic decision context. Section 3.4 describes the design features relating to the probability domain and rationale for a mixed-strategy design.

\subsection{Experiment operation and sample selection}

Remarkably few studies replicate the exact same experiment to compare university subject pools with professional market actors (Frèchette 2015, 2016). This is the case for a variety of reasons, including the financial and opportunity costs involved in utilizing professional subjects. Further, among the few existing studies, there is notable divergence between studies finding no or small qualitative difference (List 2002; List and Haigh 2005; Levitt et al. 2010) and studies finding significant qualitative differences (Burns 1985; List 2001; Palacios-Huerta and Volij 2008) between student and professional subjects.

The experiment using the two subject pools was conducted as an online experimental survey administered in two stages in late 2015 and early 2016 by RTi Research, a professional business survey firm. Professional subject experimental sessions made use of an existing subject pool of managers from a representative sample of mid-sized businesses and included mainly CEOs, COOs, owners, or executives tasked with making strategic corporate investment decisions. ${ }^{2} \mathrm{~A}$ more standard experimental economics subject pool was also used from The Ohio State University.

In October 2015, the initial run included 368 undergraduate subjects. The advice treatments that are the focus of this paper provided 298 completed experiments. ${ }^{3}$ The second run,

\footnotetext{
${ }^{2}$ Because the National Center for the Middle Market funded this research and had existing collaborations with RTi Research, we had a high degree of assurance that the subjects took the experiment seriously. More specifically, these subjects were drawn from the pool of managers who complete the Middle Market Indicator Report. For more information on the sampling pool, see the FAQ at http://www. middlemarketcenter.org/performance-data-on-the-middle-market.

3 The remaining 70 subjects were assigned to independent and alternative treatments that are not relevant for this study and address the value of information in repeated events decisions. Those are published in Dormady, Greenbaum and Young (2021).
}

carried out in January 2016, included both students (286) and managers (312). Altogether, the data set evaluated here consists of 896 subject records, including a professional subject sample of over 300, which is much larger than nearly all other experiments involving professionals in the field today.

Subjects were randomly assigned from the subject pool and also randomly assigned to treatments. The random assignment used a conditional least-count uniform distribution algorithm to assign subjects to advice treatments. Although this algorithm assigned subjects randomly using a uniform distribution, it also weighted the distribution more heavily toward those treatment and selection parameters that had the lowest count of completed surveys at that point in time. This ensured perfect equality of subject counts across treatments (as possible). We also oversampled from female subjects in both subject pools to ensure an equal gender balance in all treatments.

\subsection{Decision-making scenario}

Subjects were provided a resilience decision-making context, or vignette, in which they were asked to advise a firm's Chief Operations Officer (COO) on an important operational decision in the face of a critical supply chain vulnerability. In the possible event of an unnamed catastrophe, the firm's ability to acquire the needed production input would be substantially limited. Subjects were asked to advise the COO on an investment decision that could reduce the potential negative consequences of the production input curtailment that would occur if the catastrophic event were to ensue. The exact type of catastrophic event was not specified, as a contextualized decision could introduce exogeneity bias if subjects' individual heuristic biases (e.g., fear of hurricanes) influenced their resilience decisions.

In this experiment, if a catastrophic event were to occur, the inventory investment provides a stock of the critical input that would result in only a slight reduction in the firm's operation continuity. Subjects were thus faced with the decision of continuing to operate normally and face the risk of a catastrophic event that would nearly wipe out production capability or make an investment in inventories with an opportunity cost in the here and now that would shield the firm from probabilistic near-term operational consequences. The vignette read as follows:

You are an executive in a mid-sized business. The Chief Operating Officer (COO) has asked you to help the company make an important operation decision that will play an important role in the future success of the company.

The company faces a potential vulnerability in its supply chain. To produce its output, the company requires 
Table 1 Resilience decision payoff matrix

\begin{tabular}{|c|c|c|}
\hline \multirow[t]{2}{*}{ Resilience decision } & \multicolumn{2}{|c|}{ Event determination (exogenous) } \\
\hline & $\begin{array}{l}\text { Catastrophic event } \\
\text { occurs }\end{array}$ & $\begin{array}{l}\text { Catastrophic } \\
\text { event does not } \\
\text { occur }\end{array}$ \\
\hline Invest in inventories & $\$ 70$ million & $\$ 80$ million \\
\hline Do not invest & $\$ 10$ million & $\$ 100$ million \\
\hline
\end{tabular}

an input in order for it to be able to continue to operate. If a catastrophic event were to occur, it would wipe out the company's ability to obtain this critical input, and the company would operate on a skeleton basis until operability is restored.

The company has the option of making an investment that could limit the negative impacts of this catastrophic event. If the company purchases a large inventory of the critical input, the company could continue to function at nearly full operability. The inventory however, would incur a sizeable cost to the company. The COO has asked you to make the decision of investing in the inventory. The COO has informed you that:

- If no catastrophic event occurs, the company will have estimated profit of $\$ 100$ million.

- If a catastrophic event occurs, the company will have estimated profit of $\$ 10$ million.

- If a catastrophic event occurs, and the company has made the investment in inventories, the company's estimate profit is $\$ 90$.

- The cost of inventories is \$20 million.

Subjects were then given the decision-making payoff matrix in Table 1. Inventories incurred a cost of $\$ 20$ million per decision period. If a firm invested and a catastrophic shock occurred, the firm is only slightly negatively affected by the shock. Profits would be $\$ 70$ million per period, taking into account the inventory investment (top-left cell). If a shock were to occur, and no inventories were acquired by the firm, its operability would be severely impacted, reflecting the production capability reduction. Profits would be $\$ 10$ million per period (bottom-left cell). The right column represents the payoffs under the scenarios in which no catastrophe occurs. Under these business-as-usual conditions, the firm would have profits of $\$ 100$ million per period if inventories were not purchased (bottom-right cell). Finally, if the firm made the investment and no catastrophic shock occurs, profits would be $\$ 80$ million per period, or $\$ 100$ million minus the $\$ 20$ million cost of inventories (top-right cell).

Because the focus of our study is middle-sized businesses (as defined by annual revenues between $\$ 10$ million and $\$ 1$ billion), resilience strategies of middle-sized firms tend to be limited compared to larger companies. This is important because middle-sized businesses that make investments in redundancy or inventories, for example, tend to do so at a tradeoff to core production inputs in the present, notably investments in labor or capital. Larger firms can generally afford redundancy without the same relative opportunity cost. Moreover, in the globally competitive marketplace in which most middle-sized businesses compete, costly investments in inventories or other resilience investments can put them at a disadvantage relative to other firms that do not bear such costs or catastrophic risk.

Subject remuneration was aligned with this payoff structure, which also aligns with standard experimental practices of incentivizing performance via induced value theory. This is also consistent with corporate performance pay strategies that reward executives for management performance that is tied to market-based outcomes (Jensen and Murphy 1990). Subjects in the experiment received payment at the ratio of one dollar for every 100 million dollars the firm received in profits. ${ }^{4}$

The running calculation of remuneration was visible during the experiment; however, every other aspect of the vignette indicated the independence of decision-making periods. Specifically, inventories were not carried over from period to period, and the introduction of a new period was accompanied by the phrase, "Some time has passed. The company is again faced with the option to invest in inventories that would limit the negative impacts of the catastrophic event." This scenario signaled a new, independent time period without suggesting a type of inventory or type of disaster that could have activated individual heuristic biases, as discussed below.

\subsection{Dynamic treatment conditions}

Subjects made resilience decisions across ten two-round periods. In the first round of each period, subjects made an initial investment decision. After making their initial decision, subjects were informed that the $\mathrm{COO}$ has appointed an advisory committee of two associates with operational management expertise to assist them in making their decision on how to advise the $\mathrm{COO}$ regarding the inventory investment. However, subjects were informed that their decisions were ultimately their own.

\footnotetext{
${ }^{4}$ Subjects received a show-up payment of $\$ 5$ and a $\$ 3$ flat-rate payment for completion of a post-experiment survey. Overall, mean subject earnings were $\$ 15.76$ including these fixed rate components (\$15.78 and \$15.72 for student and professional subjects, respectively). Professional subjects also earned a flat-rate completion credit for participating, valued at approximately $\$ 60$.
} 
There were two treatments in terms of advice received from the appointed associates, either to "invest" or "do not invest" in inventories, and the advice given was consistent across the ten periods. In all cases, both of the appointed vignette advisors gave the same advice. That is, in no treatment were the subjects receiving conflicting advice from the advisory committee. ${ }^{5}$ An example vignette (for a subject who decided to not invest in the first round of a period and was assigned to the do not invest treatment) reads as follows:

Now that you have made the decision to not invest in inventories, the $\mathrm{COO}$ has appointed an advisory team of two other executives with experience in operations management. Although the decision to invest in inventories ultimately rests with you, the $\mathrm{COO}$ has asked you to consider the input of the advisory team.

The first member of the advisory team has reviewed the revenue scenario thoroughly. This team member recommends that the company not invest in inventories.

\section{This team member recommends that you not invest in inventories.}

The second member of the advisory team has also reviewed the revenue scenario thoroughly. This team member recommends that the company not invest in inventories.

\section{This team member recommends that you not invest in inventories.}

After receiving the recommendations from the advisory committee, subjects made their final decision and were subsequently informed of the disaster outcome. Subjects were not informed that the total number of periods would be ten. Therefore, subjects' resilience decisions were systematically influenced by only the advice received by advisors and by their own non-systematic subject-specific experience with the outcomes of disasters in each period. Therefore, in this experiment, our two main variables of focus are the influence of the advice and the effect of repeated events.

\subsection{Probability domain in the experimental design}

As identified in Sect. 2, the benefit of an experiment over observational data is the ability to introduce experimental control, specifically regarding the probability domain while

\footnotetext{
5 In this paper, we evaluate only these two treatments. In operation, these consisted of twelve treatments that varied the gender pronoun of the advisor ("he," "she," and "this team member") relative to the advice provided and the reported biological sex of the subject. Pronoun variance yielded no material or statistical differences in dynamic subject behavior, and we report only on the main advisory treatment design here.
}

Table 2 Expected monetary value conditional on common likelihood priors

\begin{tabular}{llll}
\hline Resilience decision & \multicolumn{3}{l}{ Expected monetary value } \\
\cline { 2 - 4 } & $\operatorname{Pr} .=0.5$ & $\operatorname{Pr} .=0.25^{\dagger}$ & $\operatorname{Pr} .=0.10$ \\
\hline $\begin{array}{l}\text { Invest in resilience } \\
\begin{array}{l}\text { Do not invest in resil- } \\
\text { ience }\end{array}\end{array}$ & $\$ 75$ million* & $\$ 77.5$ million & $\$ 79$ million \\
\hline
\end{tabular}

Table provides EMVs for possible likelihood priors subjects may have considered-the actual event likelihood utilized in the experiment was 0.25

*Indicates dominant strategy subject to prior

${ }^{\dagger}$ Indicates mixed-strategy catastrophic event probability utilized in this experiment

holding magnitude constant. We note that subjects' decision calculus inherently depends on their risk tolerance and their willingness to take preventative action (Englander 2015). However, this experimental design differs from classic risk experiments in three important ways. First, unlike many risk experiments, the subjects in this experiment are not informed of the likelihood of the shock. Second, there is no dominant strategy in equilibrium. Disasters were assigned randomly from a uniform distribution with mean 0.25 . The expected monetary value (EMV) is equivalent for either resilience investment strategy (\$77.5 million). ${ }^{6}$

Table 2 presents EMVs for this, as well as 0.5 and 0.1 , two likely subject guesses for the event likelihood. If probability were observable to subjects, risk-neutral subjects would play a mixed strategy. At the same time, risk averse subjects and subjects with likelihood priors above $25 \%$ would tend to make the investment. As such, our experimental design mirrors the real-world resilience investment decision environment faced by firms where no risk-neutral inventory investment decision is dominant.

The additional benefit of this design is that it makes treatment effects more clearly observable. Subjects' inherent priors about the likelihood of a catastrophic event and their risk preferences ultimately inform their resilience investment decisions. Subjects who believe that the likelihood of a catastrophic event is high are more likely to invest in resilience, ceteris paribus.

\section{Results}

We begin by providing some initial descriptive statistics of our results, including some basic hypothesis tests. Then, we provide more detailed subject-level panel regression

\footnotetext{
${ }^{6}$ The expected monetary value (EMV) for the Invest strategy is $0.25(\$ 70)+0.75(\$ 80)=\$ 77.5$. The EMV for the Do Not Invest strategy is $0.25(\$ 10)+0.75(\$ 100)=\$ 77.5$.
} 
Table 3 Disaster Occurrence Descriptive Statistics (percent by treatment, subject type, and period)

\begin{tabular}{|c|c|c|c|c|c|c|c|c|c|c|c|c|}
\hline \multirow[t]{2}{*}{ Treatment } & \multirow[t]{2}{*}{ Subject type } & \multirow{2}{*}{ Stat } & \multicolumn{10}{|c|}{ Period } \\
\hline & & & 1 & 2 & 3 & 4 & 5 & 6 & 7 & 8 & 9 & 10 \\
\hline \multirow[t]{4}{*}{ Do not invest } & Student & Mean & 23.6 & 26.4 & 26.0 & 20.9 & 25.0 & 24.0 & 28.1 & 24.7 & 20.5 & 26.4 \\
\hline & & St. Dev & 42.6 & 44.1 & 44.0 & 40.7 & 43.4 & 42.8 & 45.0 & 43.2 & 40.5 & 44.1 \\
\hline & Manager & Mean & 24.3 & 26.7 & 21.2 & 27.7 & 24.0 & 21.2 & 25.3 & 25.3 & 30.1 & 24.0 \\
\hline & & St. Dev & 43.0 & 44.3 & 41.0 & 44.8 & 42.8 & 41.0 & 43.6 & 43.6 & 46.0 & 42.8 \\
\hline \multirow[t]{4}{*}{ Invest } & Student & Mean & 25.0 & 25.6 & 27.6 & 23.1 & 24.4 & 22.4 & 19.2 & 28.2 & 26.9 & 25.0 \\
\hline & & St. Dev & 43.4 & 43.8 & 44.8 & 42.3 & 43.1 & 41.9 & 39.5 & 45.1 & 44.5 & 43.4 \\
\hline & Manager & Mean & 30.8 & 24.4 & 25.6 & 26.3 & 26.9 & 26.9 & 23.7 & 16.7 & 24.4 & 27.6 \\
\hline & & St. Dev & 46.3 & 43.1 & 43.8 & 44.2 & 44.5 & 44.5 & 42.7 & 37.4 & 43.1 & 44.8 \\
\hline
\end{tabular}

Disaster occurrence was drawn from a uniform distribution with $\operatorname{Pr}($ Disaster $)=0.25$
Table 4 Resilience Investment Descriptive Statistics (percent by treatment, subject type, and period)

\begin{tabular}{|c|c|c|c|c|c|c|c|c|c|c|c|c|c|}
\hline \multirow[t]{2}{*}{ Treatment } & \multirow[t]{2}{*}{ Subject type } & \multirow[t]{2}{*}{ Stat } & \multicolumn{10}{|c|}{ Period } & \multirow[b]{2}{*}{ All } \\
\hline & & & 1 & 2 & 3 & 4 & 5 & 6 & 7 & 8 & 9 & 10 & \\
\hline \multirow[t]{4}{*}{ Do not invest } & Student & Mean & 67.1 & 62.7 & 61.3 & 59.9 & 57.9 & 58.9 & 57.9 & 53.4 & 60.6 & 54.1 & 59.4 \\
\hline & & St. Dev & 47.1 & 48.5 & 48.8 & 49.1 & 49.5 & 49.3 & 49.5 & 50.0 & 48.9 & 49.9 & 49.1 \\
\hline & Manager & Mean & 62.2 & 66.7 & 57.7 & 60.3 & 60.3 & 59.0 & 59.0 & 66.0 & 60.3 & 57.7 & 60.9 \\
\hline & & St. Dev & 48.7 & 47.3 & 49.6 & 49.1 & 49.1 & 49.3 & 49.3 & 47.5 & 49.1 & 49.6 & 48.8 \\
\hline \multirow[t]{4}{*}{ Invest } & Student & Mean & 96.6 & 90.1 & 85.6 & 84.6 & 78.1 & 76.4 & 77.4 & 78.4 & 78.4 & 72.6 & 81.8 \\
\hline & & St. Dev & 18.2 & 30.0 & 35.2 & 36.2 & 41.4 & 42.6 & 41.9 & 41.2 & 41.2 & 44.7 & 38.6 \\
\hline & Manager & Mean & 74.4 & 75.6 & 79.5 & 79.5 & 77.0 & 75.0 & 76.3 & 77.6 & 79.5 & 76.9 & 77.1 \\
\hline & & St. Dev & 43.8 & 43.1 & 40.5 & 40.5 & 42.3 & 43.4 & 42.7 & 41.9 & 40.5 & 42.3 & 42.0 \\
\hline
\end{tabular}

analyses of our results. We then extend this by delving deeper into the determinants of subjects' resilience decisions by evaluating the determinants of subject affect for the advisors in terms of trust.

\subsection{Descriptive statistics}

In addition to the advice received from the advisors in the vignettes, subjects' own experience with disaster occurrence across the ten periods can influence their resilience investment decisions. Moreover, because subjects were not informed of the likelihood of disaster occurrence, their experiences with disasters on a period-by-period basis would tend to inform their perceptions of the likelihood of disaster occurrence dynamically (i.e., as they experience them over time).

To ensure that there were no systematic differences across advice treatments in either of our subject populations, we evaluate the occurrence of catastrophic events that subjects observed. Descriptive values are provided on a round-byround basis in Table 3. From these descriptive results, we have confidence that there are no systematic biases across treatments, subject populations, or rounds in terms of any group receiving more "shocks" than another. The rate of disaster occurrence varies only from a mean of $24.6 \%$ among students who received the advice to not invest to
$25.3 \%$ among the managers who were given the advice to invest, over ten periods. We also conducted parametric and non-parametric tests of means by treatment, subject type, and period, not provided here for brevity, to ensure that all subjects in each treatment and round experienced disaster likelihoods that were not statistically different from $25 \%$. $^{7}$ Across the board, all subjects in all rounds were exposed to the same shock probabilities and no systematic differences in exposure exist in our data.

We provide basic summary statistics of the experimental results by treatment group, subject type, and period, in Table 4 . The table provides mean and standard deviation for each. It also provides the total ten round averages for each. In total, 292 student subjects and 156 middle market managers received consistent advice to invest in resilience. The same

\footnotetext{
${ }^{7}$ In nearly all cases, Wilcoxon tests failed to reject the null that the percent of subjects observing a disaster was equal by advice treatment at the $p<0.05$ level. The exceptions are students in period 9 and managers in period 8 . The computer-generated randomly drawn disaster outcomes yielded slightly fewer disasters for students in the Do Not Invest treatment in period 9 and managers in the Invest treatment in period 8. In both cases, however, two-sample z-tests failed to yield statistically significant differences at the same significance level, due to the large standard deviations produced by the uniform distribution. Given the sensitivity of Wilcoxon tests, we have strong confidence that no group incurred more frequent disaster outcomes than another.
} 
Fig. 1 Mean percent of resilience investments by total count of catastrophic events by period (invest treatment)
TREATMENT: ADVICE TO INVEST IN INVENTORIES
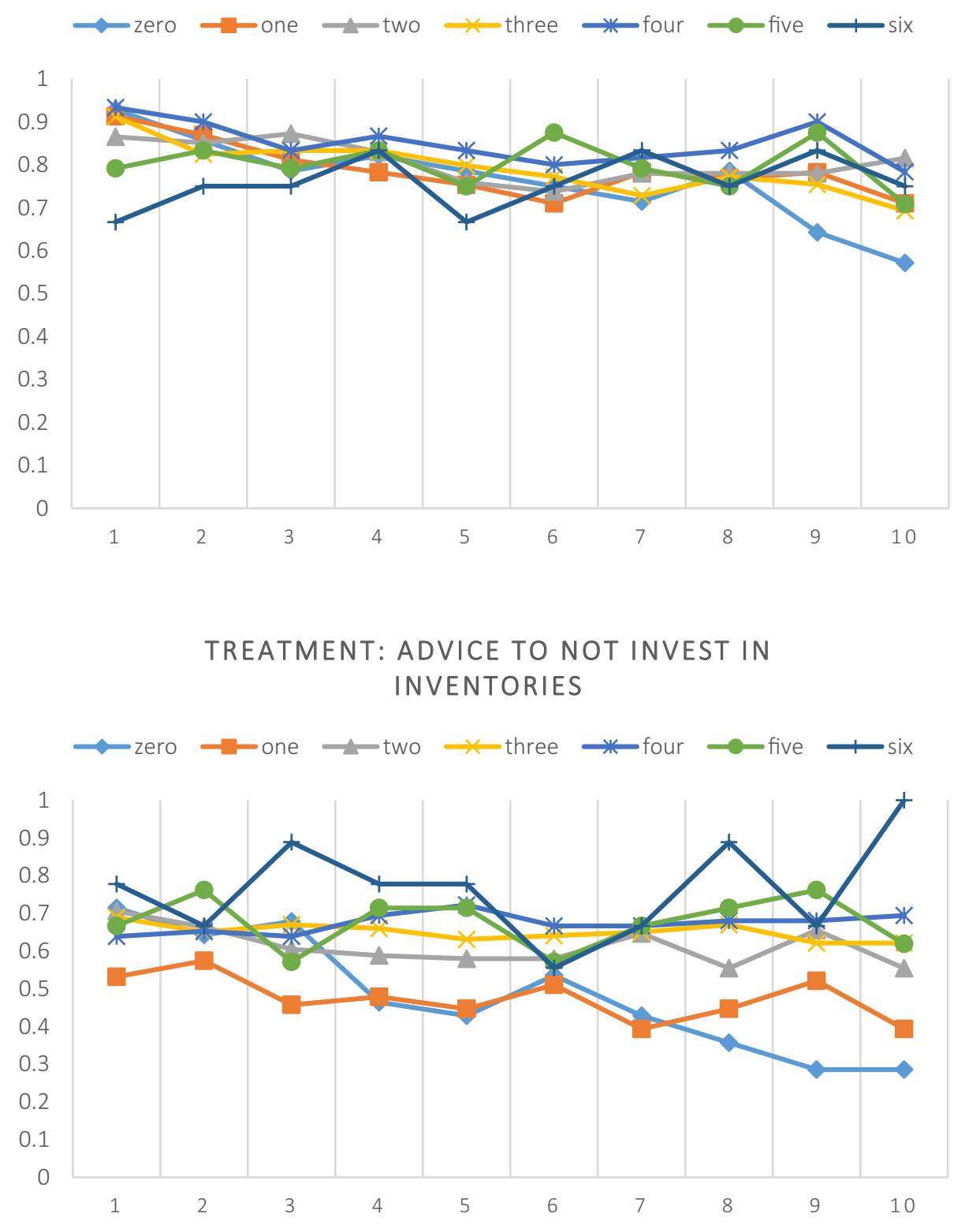

TREATMENT: ADVICE TO NOT INVEST IN INVENTORIES
Fig. 2 Mean percent of resilience investments by total count of catastrophic events by period (do not invest treatment) count of subjects, respectively, received consistent advice to not invest. From the descriptive values alone (i.e., without controlling for subject-level disaster experience), it is clear that there is a relatively strong treatment effect in both the student and manager groups-subjects who were advised in the vignettes to invest in resilience did so at a greater rate than those who were advised to not invest $(81.8 \%$ versus $59.4 \%$ among students and $77.1 \%$ versus $60.9 \%$ among managers across all ten periods). We note that even when advised to not invest, we still observe approximately six out of ten subjects making the investment. We take this as providing some evidence that subjects were either ascribing an event likelihood above $25 \%$ or viewed the investment as the risk averse option. We also note the importance of econometric controls for individual-level experience with disasters as provided in the next section. Regardless, it is the difference between the treatments that is illustrative here, as the strength of the treatment effect remains strong across ten rounds, although it appears to dissipate to a degree with increasing experience across periods.

We extend this by adding subject-level disaster exposure to the mean resilience investment results to observe the treatment effect associated with resilience investment recommendations. We first provide this graphically in Figs. 1 and 2. The Y-axis of the figures indicates the mean resilience investment decision across subjects and the $\mathrm{X}$-axis indicates the period. We provide separate line plots by the total count of disasters that subjects incurred, which ranged from zero to 
Table 5 Non-parametric tests of resilience investments (by count of catastrophic events experienced)

\begin{tabular}{lrll}
\hline $\begin{array}{l}\text { Total catastrophic events } \\
\text { experienced }\end{array}$ & $Z$-value* & $P$-value & $N$ \\
\hline Zero & $6.88^{* * *}$ & 0.000 & 560 \\
One & $12.78^{* * *}$ & 0.000 & 1,630 \\
Two & $10.94^{* * *}$ & 0.000 & 2,600 \\
Three & $7.38^{* * *}$ & 0.000 & 2,170 \\
Four & $7.40^{* * *}$ & 0.000 & 1,320 \\
Five & $2.99^{* * *}$ & 0.000 & 450 \\
Six & 0.14 & 0.889 & 210 \\
\hline
\end{tabular}

*The null hypothesis is that the mean resilience investment in the Invest treatment $=$ mean resilience investment in the Do Not Invest treatment

$* * * p<0.01, * * p<0.05, * p<0.1$

six for nearly all subjects. ${ }^{8}$ Figure 1 provides the time series averages for the Invest treatment and Fig. 2 provides them for the Do Not Invest treatment.

In comparing the two figures, we observe substantially more cohesion about the mean despite the count of disasters incurred in the Invest treatment. However, that cohesion dissipates substantially over time in the Do Not Invest treatment. The subjects incurring three or fewer disasters had the largest drop in resilience investments from the mean in the Do Not Invest treatment. This indicates that over time, realizing fewer disasters combined with receipt of a recommendation to not invest, resulted in fewer investments. This is consistent with Hertwig et al.'s (2004) speculation that the lack of experiencing rare events leads people to reduce their expectations of their occurrence. Put the other way, this suggests that recommendations to invest in resilience can have a substantial effect on encouraging resilience investments, even when subjects observe few disasters.

We extend this graphical analysis further by providing formal non-parametric tests of the equality of resilience investments by treatment. Wilcoxon (Mann-Whitney) tests are provided by the count of total disasters experienced in Table 5. In all cases except the case of six disasters experienced due to sample size and few subjects getting that many shocks, we safely reject the null hypothesis that the mean resilience investment in the Invest treatment is equal to the mean in the Do Not Invest treatment. The rarer case of six disasters falls short of common statistical significance. This provides strong evidence of a treatment effect associated

\footnotetext{
$\overline{8}$ Because the event probability was drawn randomly each period for each subject, a total of 20 subjects incurred more than six disasters, though the mean in all cases is 2.5 disasters. Ten student subjects in the Do Not Invest treatment incurred seven disasters, and ten student subjects in the same treatment incurred eight disasters.
}

with advising decision makers to invest in resilience. Next, we extend this analysis further through formal econometric estimation.

\subsection{Regression analysis}

Econometric estimation allows us to build in statistical controls to account for the repeated events aspects of the data through panel regression techniques. We use three econometric models (one static model and two dynamic models) to explain a subject's resilience investment decision. Our static econometric model (Model 1) is estimated using a random effects panel logit model given by the following equation:

$\operatorname{Pr}\left(\right.$ Invest $\left._{i t} \mid x_{i t}\right)=P\left(x_{i t} \beta+v_{i}\right)$,

where the dependent variable is the binary outcome Invest in resilience by firm $i$ in period $t$. Consistent with a random effects model, variance components are given by $v_{i}$ Explanatory variables in vector $\boldsymbol{x}$ consist of both panel/firm-invariant variables as well as time-varying variables. It is given by the following equation:

$$
\begin{aligned}
x_{i t}= & \beta_{0}+\beta_{1} \text { Disaster }_{i, t-1}+\beta_{2} \text { Cumulative }_{i, t-1} \\
& +\beta_{3} \text { Advice }_{i}+\beta_{4}\left(\text { Advice }_{i} \times \text { Accuracy }_{i, t-1}\right) \\
& +\beta_{5}\left(1-\text { Advice }_{i} \times \text { Accuracy }_{i, t-1}\right)+\beta_{6} \text { Invest }_{i, t=1}
\end{aligned}
$$

The variable Disaster indicates disaster occurrence in that period. We lag this variable by a single period, which is the most recent period observed by a subject as disaster is not observable until after the decision is made. Cumulative provides the running total count of disasters the subject has incurred in prior periods leading up to the current decisionmaking period. In other words, in any given period $t=n$, it provides $\sum_{t=1}^{n-1}$ Disaster $_{i, t}$. This variable is inherently lagged; for example, in the fifth period $(t=5)$, a subject could have experienced a max total of only four disasters by the time they make their resilience decision.

Advice is a dummy variable indicating the subjects' treatment of either Invest or Do Not Invest $(1-$ Advice $)$ in inventories. For any given subject $i$, treatment assignment is randomized and distributed Bernoulli, and it remains the same across all periods. As such, it is time invariant and no lag is necessary. We interact the treatment dummies with the variable Accuracy, which is lagged by one period. The accuracy variable captures the running total of accuracy of the advisory information the subject received. For example, if a subject in the sixth period of the invest treatment incurred one previous disaster in any preceding period, the accuracy would be 0.20 , or $1 / 5$. This allows us to incorporate the moderating effect of subjects potentially discounting advice that turns out to be erroneous over time (as well as the opposite case of high accuracy). Simply put, the interaction term allows us to measure not only the effect or our 
treatment parameter but also the dynamic effect of realized, or observed, advice accuracy as it plays out.

Finally, we include the subject's initial investment decision that provides a time-invariant binary operator for the subject's initial resilience decision at the end of the first period. We incorporate this variable as a way to account for the effect over time of subjects' adherence to their initial decision. We incorporate this variable because we observe a relatively large percentage of subjects who, after making their final decision at the first period after receiving the advisory information, never deviated from that decision despite their experience with disaster outcomes. In total, $37.6 \%$ of students and $50.9 \%$ of managers never deviated from their initial resilience investment decision.

Our dynamic econometric model (Model 2) extends our static model by incorporating two lags of the dependent variable, given by

$$
\begin{aligned}
\mathbf{x}_{i t}= & \beta_{0}+\beta_{1} \text { Invest }_{i, t-1}+\beta_{2} \text { Invest }_{i, t-2} \\
& +\beta_{3} \text { Disaster }_{i, t-1}+\beta_{4} \text { Cumulative }_{i, t-1} \\
& +\beta_{5} \text { Advice }_{i}+\beta_{6}\left(\text { Advice }_{i} \times \text { Accuracy }_{i, t-1}\right) \\
& +\beta_{7}\left(1-\text { Advice }_{i} \times \text { Accuracy }_{i, t-1}\right)+\beta_{8} \text { Invest }_{i, t=1} .
\end{aligned}
$$

Dynamic models are provided because of the nature of repeated events in the experiment-a subject's resilience investment decision in the last period or two is likely to accurately predict their resilience investment decision in the current period.

We note that dynamic random effects panel models (i.e., with lagged dependent variables) have been identified in the econometrics and epidemiology literature to have the potential to produce biased coefficients. This is because they violate the assumption that the dependent variable is not correlated with the random intercept (Nickell 1981; Bhargava and Sargan 1983; Allison 2015; Kripfganz 2016). Given the potential explanatory power of dynamic decisions in this experimental environment, and given the importance of time-invariant explanatory variables that could not be evaluated using a fixed effects approach, we take two steps to ensure that our coefficients are consistently estimating treatment effects. First, we provide both the dynamic and non-dynamic models. Second, we estimate a dynamic generalized estimating equation for our third model (Model 3), as described in Liang and Zeger (1986), as a robustness check. Here, we fit our dynamic model (Model 2) to a panel generalized linear model (GLM) given by the link function $L$ :

$L\left\{E\left(\right.\right.$ Invest $\left.\left._{i t}\right)\right\}=\left(\mathbf{x}_{i t} \beta\right)$,

where the distribution family of $L$ is a logit function distrib-

\begin{tabular}{|c|c|c|c|}
\hline Variables & $\begin{array}{l}\text { (1) } \\
\text { RE Logit }\end{array}$ & $\begin{array}{l}\text { (2) } \\
\text { RE Logit }\end{array}$ & $\begin{array}{l}\text { (3) } \\
\text { GEE Logit }\end{array}$ \\
\hline Resilience investment $_{t-1}$ & & $\begin{array}{l}2.119 * * * \\
(0.214)\end{array}$ & $\begin{array}{l}2.041 * * * \\
(0.136)\end{array}$ \\
\hline Resilience investment $_{t-2}$ & & $\begin{array}{l}1.822 * * * \\
(0.183)\end{array}$ & $\begin{array}{l}1.749 * * * \\
(0.117)\end{array}$ \\
\hline Disaster occurred $_{t-1}$ & $\begin{array}{l}0.478 * * * \\
(0.0480)\end{array}$ & $\begin{array}{l}0.471 * * * \\
(0.0466)\end{array}$ & $\begin{array}{l}0.580 * * * \\
(0.041)\end{array}$ \\
\hline Cumulative count of disasters $t_{t-1}$ & $\begin{array}{l}0.961 \\
(0.0406)\end{array}$ & $\begin{array}{l}0.996 \\
(0.0501)\end{array}$ & $\begin{array}{l}0.997 \\
(0.037)\end{array}$ \\
\hline Advice & $\begin{array}{l}0.856 \\
(0.288)\end{array}$ & $\begin{array}{l}0.218 * * * \\
(0.0857)\end{array}$ & $\begin{array}{l}0.300 * * * \\
(0.085)\end{array}$ \\
\hline Advice $*$ accuracy $_{t-1}$ & $\begin{array}{l}2.592 * * * \\
(0.892)\end{array}$ & $\begin{array}{l}3.975 * * * \\
(1.747)\end{array}$ & $\begin{array}{l}3.048 * * * \\
(0.995)\end{array}$ \\
\hline $\begin{array}{l}\text { Advice to not invest * } \\
\text { accuracy }_{t-1}\end{array}$ & $\begin{array}{l}0.110 * * * \\
(0.0364)\end{array}$ & $\begin{array}{l}0.0396 * * * \\
(0.0170)\end{array}$ & $\begin{array}{l}0.096 * * * \\
(0.029)\end{array}$ \\
\hline Initial investment decision $_{t=1}$ & $\begin{array}{l}19.19 * * * \\
(4.735)\end{array}$ & $\begin{array}{l}6.891 * * * \\
(1.513)\end{array}$ & $\begin{array}{l}3.379 * * * \\
(0.412)\end{array}$ \\
\hline Constant & $\begin{array}{l}1.090 \\
(0.399)\end{array}$ & $\begin{array}{l}2.126^{*} \\
(0.868)\end{array}$ & $\begin{array}{l}1.661 * \\
(0.478)\end{array}$ \\
\hline Wald $\chi^{2}$ & $277.64 * * *$ & $480.46 * * *$ & $553.6^{* * *}$ \\
\hline Log likelihood & -3500.42 & -3102.02 & $\mathrm{n} / \mathrm{a}$ \\
\hline Observations & 8064 & 7168 & 7168 \\
\hline Subjects $(N)$ & 896 & 896 & 896 \\
\hline
\end{tabular}
uted binomial. We use an exchangeable correlation matrix, given by $\mathbf{R}_{t, s}$, such that
Table 6 Regression results for investment in resilience (all subjects)

All models report odds ratios and standard errors in parentheses. Model 1 provides static model and models 2 and 3 provide dynamic models with two lags of the dependent variable. Model 3 provides a repeated-measures generalized estimating equations model (xtgee in Stata 14) using logit link function. Treatments in which subjects received advice to not invest in resilience are the excluded reference category for the dummy variable Advice

$* * * p<0.01, * * p<0.05, * p<0.1$

$\mathbf{R}_{t, s}=\left\{\begin{array}{l}1 \text { if } t=s \\ \rho \text { otherwise }\end{array}\right.$,

where the diagonal elements are unity and the off-diagonal elements are correlation values rho. This is useful as it provides logit odds ratios with an exchangeable correlation matrix and relaxes the assumption that lags are independent of one another (Zeger et al. 1988; Hanley et al. 2003; Gunasekara et al. 2014). This approach provides the same estimators as a dynamic population-averaged panel logistic regression. Coefficients in each model are all in general agreement and each serve to validate the direction and magnitude of treatment effects. Because the estimator in Model 3 does not allow for clustering, we do not cluster Models 1 and 2 for uniformity but note that alternative specifications utilizing subject-level clustering obtain highly similar results. 
Table 7 Regression results for investment in resilience (managers)

\begin{tabular}{|c|c|c|c|}
\hline Variables & $\begin{array}{l}\text { (1) } \\
\text { RE Logit }\end{array}$ & $\begin{array}{l}\text { (2) } \\
\text { RE Logit }\end{array}$ & $\begin{array}{l}\text { (3) } \\
\text { GEE Logit }\end{array}$ \\
\hline Resilience investment $_{t-1}$ & & $\begin{array}{l}1.950 * * * \\
(0.343)\end{array}$ & $\begin{array}{l}2.014 * * * \\
(0.239)\end{array}$ \\
\hline Resilience investment $_{\mathrm{t}-2}$ & & $\begin{array}{l}1.263 \\
(0.224)\end{array}$ & $\begin{array}{l}1.366 * * * \\
(0.162)\end{array}$ \\
\hline Disaster occurred $_{t-1}$ & $\begin{array}{l}0.601 * * * \\
(0.110)\end{array}$ & $\begin{array}{l}0.598 * * * \\
(0.111)\end{array}$ & $\begin{array}{l}0.711 * * * \\
(0.084)\end{array}$ \\
\hline Cumulative count of disasters ${ }_{t-1}$ & $\begin{array}{l}0.997 \\
(0.0770)\end{array}$ & $\begin{array}{l}1.054 \\
(0.0984)\end{array}$ & $\begin{array}{l}1.028 \\
(0.061)\end{array}$ \\
\hline Advice & $\begin{array}{l}3.563 * * \\
(2.224)\end{array}$ & $\begin{array}{l}2.456 \\
(1.914)\end{array}$ & $\begin{array}{l}1.379 \\
(0.667)\end{array}$ \\
\hline Advice $^{*}$ accuracy $_{t-1}$ & $\begin{array}{l}1.963 \\
(1.186)\end{array}$ & $\begin{array}{l}1.423 \\
(1.203)\end{array}$ & $\begin{array}{l}1.484 \\
(0.786)\end{array}$ \\
\hline $\begin{array}{l}\text { Advice to not invest * } \\
\text { accuracy }_{t-1}\end{array}$ & $\begin{array}{l}0.329 * \\
(0.193)\end{array}$ & $\begin{array}{l}0.235^{*} \\
(0.190)\end{array}$ & $\begin{array}{l}0.371^{*} \\
(0.190)\end{array}$ \\
\hline Initial investment decision $_{t=1}$ & $\begin{array}{l}73.80 * * * \\
(31.75)\end{array}$ & $\begin{array}{l}33.17 * * * \\
(15.71)\end{array}$ & $\begin{array}{l}6.133 * * * \\
(1.283)\end{array}$ \\
\hline Constant & $\begin{array}{l}0.239 * * \\
(0.151)\end{array}$ & $\begin{array}{l}0.268 * \\
(0.204)\end{array}$ & $\begin{array}{l}0.454^{*} \\
(0.216)\end{array}$ \\
\hline Wald $\chi^{2}$ & $118.41 * * *$ & $150.59 * * *$ & $172.63 * * *$ \\
\hline Log likelihood & -1073.96 & -945.33 & $\mathrm{n} / \mathrm{a}$ \\
\hline Observations & 2808 & 2496 & 2496 \\
\hline Subjects $(N)$ & 312 & 312 & 312 \\
\hline
\end{tabular}

All models report odds ratios and standard errors in parentheses. Model 1 provides static model and models 2 and 3 provide dynamic models with two lags of the dependent variable. Model 3 provides a repeated-measures generalized estimating equations model (xtgee in Stata 14) using logit link function. Treatments in which subjects received advice to not invest in resilience are the excluded reference category for the dummy variable Advice

$* * * p<0.01, * * p<0.05, * p<0.1$

We provide our regression results for all subjects in Table 6. We also provide separate results of the same models for middle market managers only in Table 7, and our student subject pool only in Table 8 . Each table provides Models 1-3.

Coefficients are presented as odds ratios. Recall that the odds ratio (OR) is interpreted as a deviation from unit value (so OR $>1$ is a positive effect on resilience investment, $\mathrm{OR}<1$ is a negative effect, and $\mathrm{OR}=1$ is a neutral effect). In all models and for both subject pools, we find consistent negative resilience investment associated with the occurrence of a disaster in the prior period. Coefficient magnitude is relatively consistent across all specifications and across both populations. The implications of this are namely that decision makers are much less likely to expend financial resources on resilience investments when a catastrophic event has just passed. In other words, subjects are heavily discounting the likelihood of a second disaster after the first
Table 8 Regression results for investment in resilience (students)

\begin{tabular}{|c|c|c|c|}
\hline Variables & $\begin{array}{l}\text { (1) } \\
\text { RE Logit }\end{array}$ & $\begin{array}{l}\text { (2) } \\
\text { RE Logit }\end{array}$ & $\begin{array}{l}\text { (3) } \\
\text { GEE Logit }\end{array}$ \\
\hline Resilience investment $_{t-1}$ & & $\begin{array}{l}2.233 * * * \\
(0.275)\end{array}$ & $\begin{array}{l}2.044 * * * \\
(0.166)\end{array}$ \\
\hline Resilience investment $_{t-2}$ & & $\begin{array}{l}2.168 * * * \\
(0.261)\end{array}$ & $\begin{array}{l}1.954 * * * \\
(0.160)\end{array}$ \\
\hline Disaster occurred $_{t-1}$ & $\begin{array}{l}0.432 * * * \\
(0.052)\end{array}$ & $\begin{array}{l}0.432 * * * \\
(0.051)\end{array}$ & $\begin{array}{l}0.519 * * * \\
(0.047)\end{array}$ \\
\hline Cumulative count of disasters $t_{t-1}$ & $\begin{array}{l}0.949 \\
(0.048)\end{array}$ & $\begin{array}{l}0.979 \\
(0.059)\end{array}$ & $\begin{array}{l}0.986 \\
(0.047)\end{array}$ \\
\hline Advice & $\begin{array}{l}0.464 * \\
(0.186)\end{array}$ & $\begin{array}{l}0.087 * * * \\
(0.039)\end{array}$ & $\begin{array}{l}0.140 * * * \\
(0.051)\end{array}$ \\
\hline Advice $*$ accuracy $_{t-1}$ & $\begin{array}{l}2.979 * * * \\
(1.244)\end{array}$ & $\begin{array}{l}5.739 * * * \\
(2.922)\end{array}$ & $\begin{array}{l}4.457 * * * \\
(1.867)\end{array}$ \\
\hline $\begin{array}{l}\text { Advice to not invest * } \\
\text { accuracy }_{t-1}\end{array}$ & $\begin{array}{l}0.062 * * * \\
(0.025)\end{array}$ & $\begin{array}{l}0.019 * * * \\
(0.009)\end{array}$ & $\begin{array}{l}0.045^{* * *} \\
(0.017)\end{array}$ \\
\hline Initial investment decision $_{t=1}$ & $\begin{array}{l}9.802 * * * \\
(3.332)\end{array}$ & $\begin{array}{l}3.559 * * * \\
(0.929)\end{array}$ & $\begin{array}{l}2.454 * * * \\
(0.432)\end{array}$ \\
\hline Constant & $\begin{array}{l}2.562 * * \\
(1.209)\end{array}$ & $\begin{array}{l}5.299 * * * \\
(2.650)\end{array}$ & $\begin{array}{l}3.604 * * * \\
(1.363)\end{array}$ \\
\hline Wald $\chi^{2}$ & $175.22 * * *$ & $364.84 * * *$ & $404.33 * * *$ \\
\hline Log likelihood & -2406.19 & -2127.46 & $\mathrm{n} / \mathrm{a}$ \\
\hline Observations & 5256 & 4672 & 4672 \\
\hline Subjects $(N)$ & 584 & 584 & 584 \\
\hline
\end{tabular}

All models report odds ratios and standard errors in parentheses. Model 1 provides static model and models 2 and 3 provide dynamic models with two lags of the dependent variable. Model 3 provides a repeated-measures generalized estimating equations model (xtgee in Stata 14) using logit link function. Treatments in which subjects received advice to not invest in resilience are the excluded reference category for the dummy variable Advice

$* * * p<0.01, * * p<0.05, * p<0.1$

has passed. This behavior is consistent with the gambler's fallacy notion that people misattribute the characteristics of the small sample of lived experiences to the larger underlying probability distribution (Tversky and Kahneman 1971).

This result also provides validation of our experimental design. It was our intent to design a decision environment that was simultaneously strategy neutral and that incorporated the real-world institutional feature of inventories bearing an opportunity cost in the here and now. Because we observe an odds ratio consistently less than one associated with Disaster in all models, this provides some evidence that our experimental design is capturing this effect and that subjects are attempting to avoid having to make the investment.

This also has important implications for the business population of our manager subject pool-mid-sized businesses. While the largest firms are able to underwrite their own losses, mid-sized firms face a much more competitive 
Fig. 3 Predictive margins of resilience investment, by accuracy of advice (all subjects).

Horizontal line indicates mean predictive margin for treatment when accuracy of advice is held at the mean
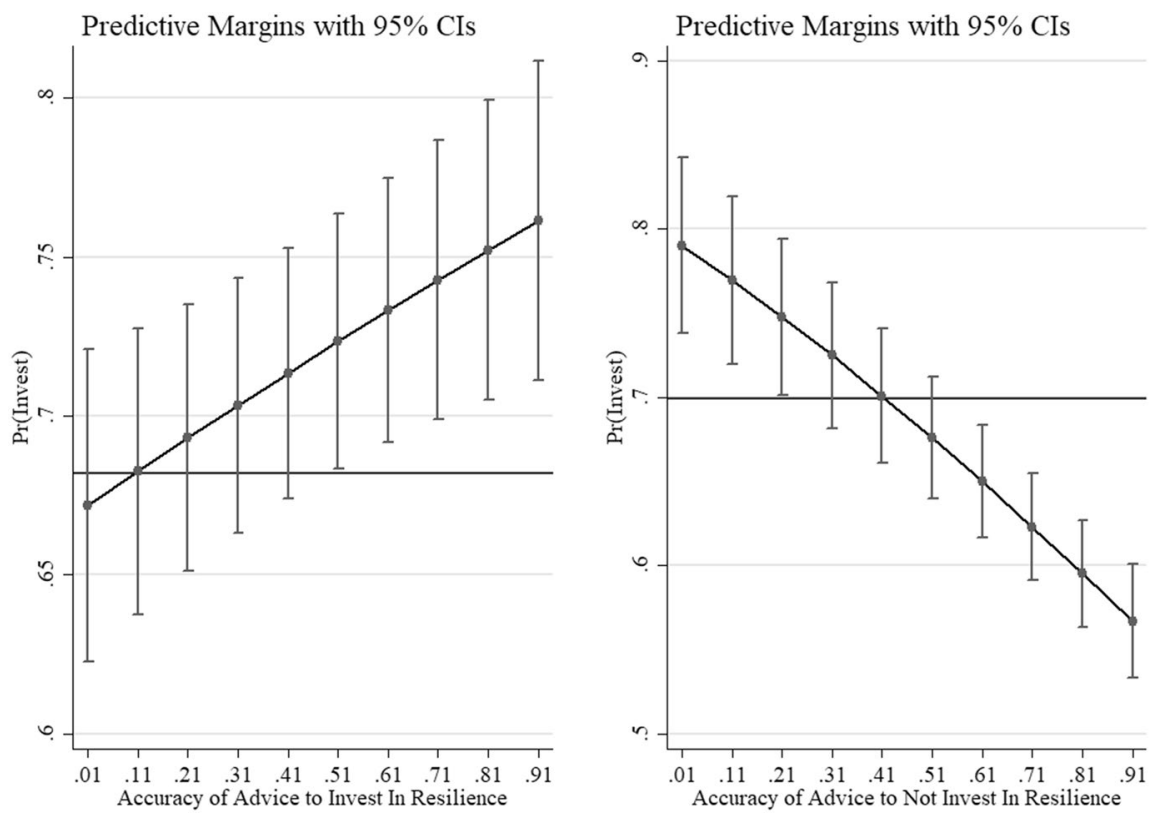

business climate and are forced to compete both nationally and globally against firms that may not face the same degree of catastrophic risk. Resilience expenditures, such as inventories, may put these firms in particular, at a competitive disadvantage (Young et al. 2017). It is key to the external validity of our experiments that we consistently observe this effect of subjects seeking to avoid the opportunity cost of resilience investments. Any other directional effect of this coefficient would indicate that our data are not picking up real-world opportunity costs of inventories.

Our treatment variable Advice provides interesting but mixed results. While the reference group is the Do Not Invest treatment, we expect the coefficient Advice to be greater than one. However, we observe this only for managers in Model 1 , when a lagged dependent variable is not incorporated into the model. However, the two interactive terms in which the treatment dummy is interacted with Accuracy are generally significant at the $10 \%$ level and in the expected direction, with the exception of accuracy of advice to invest for managers, which falls short of generally accepted levels of statistical significance.

Critically important to understanding these results are the following. We note the importance of the magnitude of these two interactive variables in light of our disaster probability of 0.25 . Given that subjects all consistently faced a $25 \%$ likelihood of disaster occurrence, the advisory information in the Advice (advised to invest) treatment would be incorrect relative to the advisory information provided in the Do Not Invest treatment at a ratio of $3: 1$. Thus, it is important that we consider the impact of the treatment variable in light of the accuracy of the information as it is revealed across time to the subjects.
Keeping this important consideration in mind, we expect accurate advice to invest in resilience to have a positive effect on resilience investments. Contrariwise, we expect accurate advice to not invest in resilience to have a negative effect. This result obtains and in the expected direction in all cases. This effect is statistically significant in all models except the accuracy of advice to invest among managers as just mentioned. We note that across the board, the contrast between the direction of magnitude of these two interactive coefficients is quite large. This provides evidence that decision makers respond in accordance with accurate advisory information. Taken together with our main treatment dummy Advice, these results suggest that advisory information alone is not sufficient to encourage resilience investments-that information must also be substantiated with a history of accuracy.

We can extend the description of our treatment effects further by evaluating the marginal effects of the treatment interaction variables. While logit coefficients are not as easily interpreted as OLS coefficients, we generate predictive margins for specified parameters in our estimating equation. We illustratively provide margins plots in Figs. 3 and 4 for all subjects and managers respectively. We exclude the plot for our student population for brevity as it is very similar to Fig. 3. The Y-axis provides the predicted probability that the decision-maker will invest in resilience as fitted by Model 1 , holding all other variables constant at their means. The $\mathrm{X}$-axis provides Accuracy $_{t-1}$ as provided in the regression model. The panels on the left of Figs. 3 and 4 provide the predictive margins for the Invest treatment, and the panels on the right, the Do Not Invest treatment. The whiskers indicate the upper and lower bounds of a $95 \%$ confidence interval 
Fig. 4 Predictive margins of resilience investment, by accuracy of advice (managers). Horizontal line indicates mean predictive margin for treatment when accuracy of advice is held at the mean

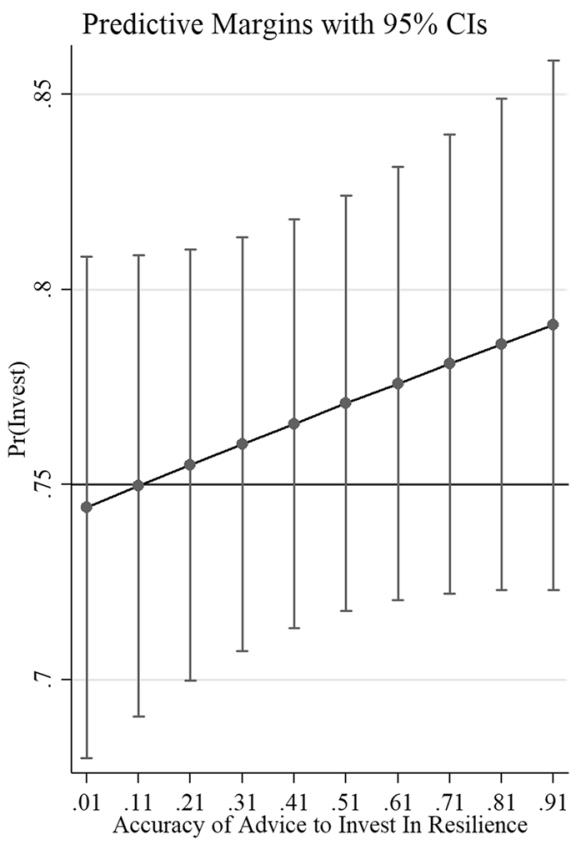

about each predictive point estimate. Further, we provide the mean predictive margins for each treatment as a horizontal reference line.

The Invest treatment marginal effects have a positive slope in the expected direction indicating that as advisory information encouraging resilience investments increases in accuracy, the probability of a decision maker investing in resilience increases. The Do Not Invest treatment is also in the expected direction, with a negative slope revealing the opposite effect. Whereas the confidence intervals are broader for the manager plots, as they are in the regression models, this is due to two main effects-the smaller sample size of our manager pool and the relatively larger magnitude of the mean value of initial investment decision (Invest ${ }_{t=1}$ ) indicating that managers deviated less from their initial resilience investment decision in response to advisory information. We also note the steeper slope of the marginal effects of the Do Not Invest treatment. This again indicates that decision makers are averse to incurring the opportunity costs of inventories, and are more likely to not invest in inventories when their experience with disasters not occurring is congruent with advisory recommendations to not invest in inventories.

As previously mentioned, many subject's investment decisions were time invariant or nearly so. Thus, in all models, the odds ratio for the initial decision variable is greater than one and statistically significant. Subjects who made the initial decision to invest in inventories had a significantly higher likelihood of continuing to invest in inventories, even after controlling for the volume of disasters experienced and the advisory information received. Additionally, because it is a dummy variable, the opposite case obtains for those subjects who initially decided to not invest in inventories. We also note that the magnitude of this odds ratio declines markedly when lagged DVs are incorporated, and particularly when GEE models are used because they relax the assumption that lags are independent of one another. This indicates that when dependence between decisions across rounds is permitted, the relative importance of the initial resilience decision diminishes.

The variable Cumulative Count of Disasters falls short of statistical significance in all models. While we would expect that decision makers faced with increasing disaster frequency would be more likely to invest in resilience to reduce loss risk going forward, an equally plausible hypothesis would suggest that decision makers view multiple recent disasters as evidence that they will be far more infrequent going forward as they have already beaten the odds. We therefore retain this variable in the model as a control, but do not necessarily maintain an expectation for its direction of effect or statistical significance.

The count of disasters does however provide for a meaningful way to view the treatment effects more broadly. By viewing the treatment effects of Advice by the running count of disasters, we can observe the degree to which the advisory information is persistent over the range of potential disaster outcomes, including the mean of 2.5 disasters. We provide this in margins plots in Figs. 5 and 6 for all subjects and managers, respectively. Again, these marginal effects hold all other values constant at their means-including the accuracy of the advisory information. While the slopes of the marginal effect plots are not statistically different from zero, the marginal effects and accompanying confidence intervals 




Fig. 5 Predictive margins of resilience investment, by lagged cumulative count of disasters experienced, by treatment (all subjects)

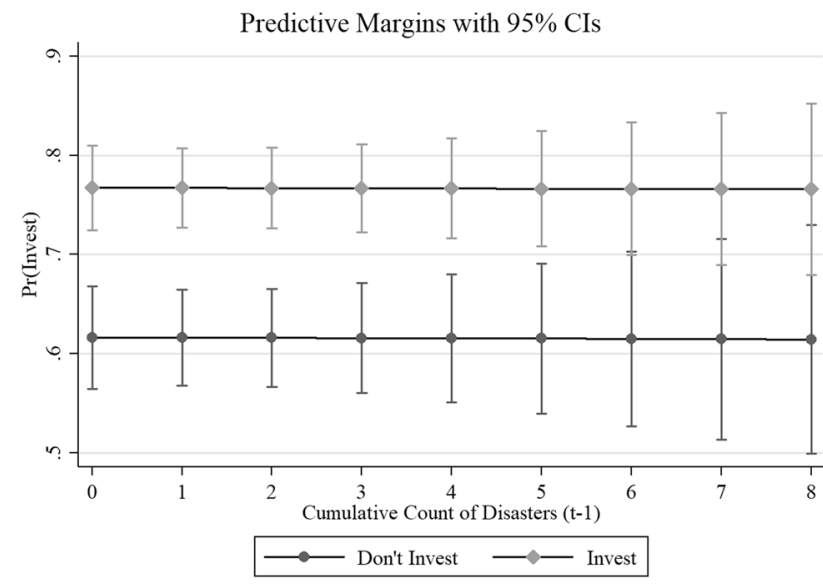

Fig. 6 Predictive margins of resilience investment, by lagged cumulative count of disasters experienced, by treatment (managers)

indicate that the regression model has predicted statistically significant treatment differences for up to eight disasters for all subjects (the maximum incurred by any subject), and five for the manager models. As appropriate, because the sample size of subjects incurring more than 2.5 disasters dissipates with an increasing number of disasters, the confidence intervals of the predictive margins widen as the count of disasters increases. These plots provide an accessible visualization of our regression results. They indicate that clear treatment effects obtain for the effect of advisory information on resilience investments, even accounting for relatively frequent disaster outcomes.
Table 9 Regression results for advisor trust (post final round)

\begin{tabular}{llll}
\hline Variables & $(1)$ & $(2)$ & $(3)$ \\
& All Subjects & Managers & Students \\
\hline Advice * accuracy & $29.767^{* * *}$ & $21.612^{*}$ & $48.970 * * *$ \\
& $(25.18)$ & $(25.109)$ & $(50.997)$ \\
Advice to not invest * accuracy & $0.476^{* *}$ & 0.605 & $0.435^{* *}$ \\
& $(0.148)$ & $(0.247)$ & $(0.164)$ \\
Disaster count total & $0.736^{* * *}$ & 0.872 & $0.664 * * *$ \\
& $(0.0433)$ & $(0.092)$ & $(0.051)$ \\
Constant & $3.421^{* * *}$ & $3.465 * * *$ & $3.337 * * *$ \\
& $(0.825)$ & $(1.556)$ & $(0.962)$ \\
Pseudo $R^{2}$ & 0.09 & 0.05 & 0.12 \\
Log likelihood & -535.80 & -170.83 & -350.26 \\
Observations & 896 & 312 & 584 \\
\hline
\end{tabular}

Logit models reporting odds ratios and standard errors in parentheses for the final round (round \#10). Model 1 provides results for all subjects, and models 2 and 3 provide results for managers and students, respectively

$* * * p<0.01, * * p<0.05, * p<0.1$

\subsection{Trust in resilience advice}

We also administered a small battery of questions in a postexperiment survey to elicit a richer understanding of subject rationale for resilience decisions and their perceptions of the experiment more broadly. Here, we report an important measure of subject affect toward the advisor-trust. We asked subjects a simple binary question: did you trust the advisors? Overall, $63.4 \%$ of subjects reported trusting the advisors. However, while $47.9 \%$ of subjects in the Do Not Invest treatment report trusting the advisors, $78.8 \%$ of subjects in the Invest treatment report trusting the advisors.

Aside from random heterogeneity in individual subjectlevel affect (e.g., an individual's own experiences with advisory boards), systematic influences in subject-level trust here could be influenced by a subject's own experience with disasters during the ten periods in light of the advisory information given (i.e., Accuracy), or the vignette itself that introduced the advisors as experts appointed by the $\mathrm{COO}$ (which was held constant). Thus, while the effect of the vignette remains constant throughout all treatment groups, and while subject's own heterogeneity should be negligible due to assignment, accuracy of advisory information can be assessed with a high degree of control.

We evaluate subject-level trust of advisory information by conducting regression analysis on each subject's final postexperiment (i.e., period 10) data. By the end of the tenth period, each subject's disaster outcomes and accuracy of advisory information have been fully experienced, and it is at this point in the subjects' timeline that they indicated in the post-survey their trust. Table 9 provides the results of this cross-sectional logit model for each of our subject 
Fig. 7 Predictive margins of trust for advisors by accuracy of advice (all subjects)



samples and all subjects in total. We include our interactive treatment variables indicating the effect of accurate advisory information in each treatment, and we include the total count of disasters experienced. Again, each model reports coefficients as odds ratios.

The regression results indicate that subjects overwhelmingly trust accurate advice to invest in resilience. The results also, however, indicate that subjects distrust accurate advice to not invest in resilience. Both of these findings are consistent with Slovic's (1999) notion that people are more likely to trust sources of bad news (in this case, the advice to invest in inventories because of an impending negative event) than to trust sources of good news (in this case, the message that there is no need to invest). The results also indicate that subjects were increasingly distrustful of advisory information as they incurred more disasters, again consistent with the notion that events that betray trust are more perceptible to individuals (Slovic 1999).

This result is consistent with expectations in terms of accuracy of advice to invest in resilience. More accurate advice that turns out, over time, to provide a cautionary recommendation that benefits the decision maker should, on balance, be more favorably received. However, because of the relationship between the measure of accuracy and the count of disasters experienced, advisory information in the Do Not Invest treatment would be of lower accuracy for a larger count of total disasters experienced than for fewer disasters experienced. Thus, these results indicate that subjects have positive affect for advisory information to invest in resilience. This affect may stem from the fact that subjects perceive advisory information to invest as cautionary or protective.
We provide the predictive margins as plots in Figs. 7, 8, 9 , and 10. Figure 7 provides the predictive margins of trust as a function of accuracy of advisory information by treatment group for all subjects, and Fig. 8 provides these results for managers (again student plots are omitted for brevity as they are quite similar to the plots for all subjects). Figure 9 provides the predictive margins by the total count of disasters experienced for all subjects, and Fig. 10 provides the same for managers. While the raw mean value of trust for all subjects is $63.4 \%$, it is 58.0 and $73.4 \%$ for students and managers, respectively. Given that the mean accuracy of advice to invest in resilience should be 0.25 for the average subject in the Invest treatment, and given that the mean accuracy of advice to not invest in resilience should be 0.75 for the average subject in the Do Not Invest treatment, we can evaluate the predictive margins at those values to compare the treatment effects.

At those margins, the predicted probability that a subject would trust that advisory information to Invest is $72.9 \%$, and the predicted probability that a subject trusts the advisory information to Not Invest is $58.1 \%$. For managers, these values are $81.2 \%$ and $70.5 \%$. And for students, they are $68.7 \%$ and $51.7 \%$. Across the board, therefore, there is a nearly $15 \%$ greater probability that a subject trusts advisory information to invest in resilience than advisory information to not invest in resilience, even after accounting for the subject's experience with prior disasters. 
Fig. 8 Predictive margins of trust for advisors by accuracy of advice (managers)

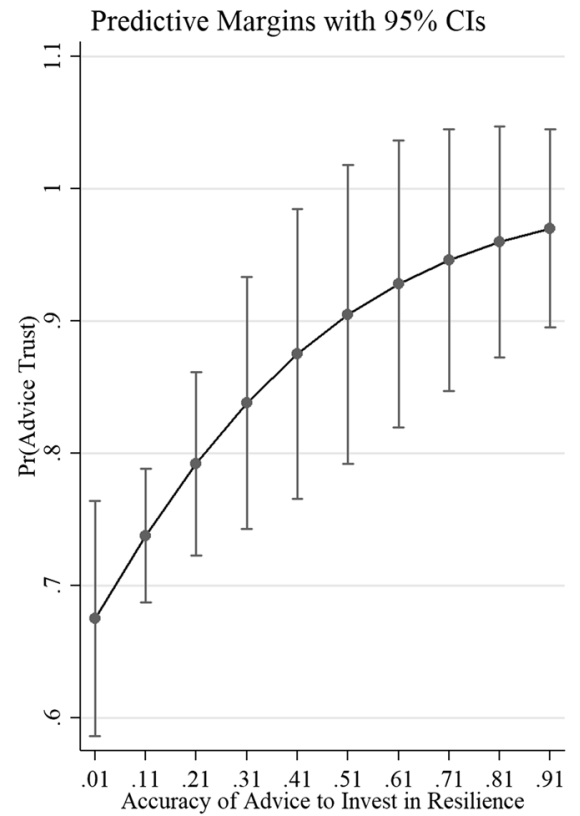



Fig. 9 Predictive margins of trust for advisors by count of disasters experienced by treatment (after ten rounds, all subjects)

\section{Discussion}

\subsection{Summary}

Four key empirical findings of this study contribute to the knowledge gap regarding how individual decision makers make resilience investments related to the potential for repeated catastrophic events. First, our results are consistent with some of the cognitive biases that have been identified in earlier research. Both manager and student decision makers are much less likely to invest in economic resilience after a catastrophic event has just occurred. When facing the potential for another event, subjects appear to discount the probability in the next round based on their

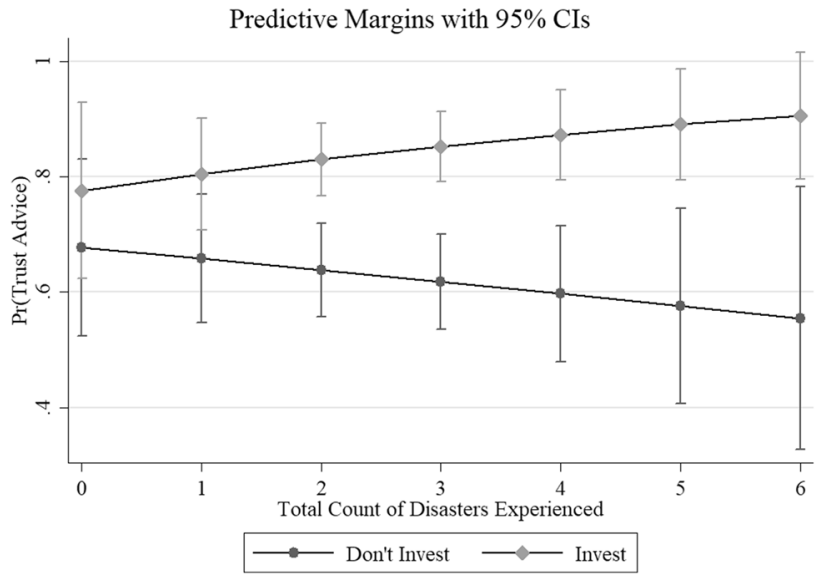

Fig. 10 Predictive margins of trust for advisors by count of disasters experienced by treatment (after ten rounds, managers)

experience of an event immediately prior. We, thus, show that resilience investment decisions made with the potential for repeated catastrophic events are consistent with the recency bias and gambler's fallacy elements of prospect theory (Tversky and Kahneman 1971; Kahneman and Tversky 1979). This study also provides evidence of confirmation bias in resilience investment. Subjects overwhelmingly chose to invest in resilience initially, then subsequently reported increased trust of advice to make resilience investments.

While findings consistent with prospect theory are not novel, more notable is that we find in our multiple-round randomized experiment that the provision of advice can moderate the biases decision makers may harbor and can even 
affect how perceptions of risk are updated. Our second key empirical finding is that advice to decision makers to invest in economic resilience can help maintain resilience investments even for those experiencing a shock infrequently. In the first period, before subjects received any advice, $84.7 \%$ of subjects chose to invest in resilience (Young et al. 2017). Third, we find that advice sustains cohesion about this high mean over subsequent rounds for every group except those who experienced zero shocks. Advice to not invest in inventories proves similarly influential, as it appears to prompt investment dissipation. Comparing advice to invest and advice to not invest, dissipation is larger for subjects who received advice to not invest coupled with a lack of disaster experience. Together, these results emphasize the influence of advice on economic resilience investments. Finally, we discover that advisory information must be substantiated with a history of accuracy to be optimally effective and that not all information is similarly received. Subjects show a $15 \%$ greater probability of trusting advice to invest compared to advice to not invest.

\subsection{Limitations}

While the use of a controlled experiment is the only practical way to test our hypotheses regarding resilience decision making in the face of repeated hazard threat and the related role of advice, it is also important to acknowledge that there are limitations to vignette-based online experiments. While the subjects have real skin in the game by virtue of remuneration based on their performance in the experiment, a few dollars lower payout as a result of experiencing a hypothetical disaster is not the same as managing through an actual catastrophic event. Likewise, a lower payout due to investing in resilience and not experiencing the disaster is different than having to justify to actual shareholders or bosses why profits were reduced in preparation for an event that never transpired. These pragmatic implications of resilienceenhancing expenditures are playing out as businesses grapple with recommendations of resilience officers above and beyond standard risk management practices. It is reasonable to assume that in practice, executives in an experiment like this one would be more contextualized to the decision environment, while students may treat the experiment more like a game. It is heartening to find similar results and effects for both groups in these experiments.

\subsection{Conclusions}

Practically, the results suggest a role for public sector leaders in fostering a resilient economy, particularly because of the important microlinkages between firm and community resilience. They also help inform the strategies of public leaders tasked with emergency management and recovery.
These government agencies and organizations should incorporate consideration for the heterogeneity among firms in how they will receive and process advice based on their own disaster experiences. ${ }^{9}$ While larger firms have the resources to explicitly invest in resilience, they also often are implicitly more resilient by virtue of operating in multiple locations at a larger and less lean scale. In this study, heterogeneity manifests as a tendency to overemphasize the status quo for decision makers that had not experienced any catastrophic events.

Much of the scholarly work on economic resilience has tended to focus on single, rather than repeated events, because of the confounding factors that affect areas that are subject to multiple disasters. These findings, that advice and repeated events are both influential in resilience investment decisions, have important scholarly and practical implications. The experiment was framed such that neither the decision to invest or not invest in resilience was a less risky option. Regardless of which decision the experimental subjects viewed as less risky and hazards they experienced, advice, and particularly more accurate advice, helped to overcome decision-making biases.

This type of work may inform how advice is given in the presence of over-investment or under-investment in resilience. Under-investment is a current public policy issue. Despite frequent and severe natural and human-induced disasters, many businesses fail to adequately invest in resilience. This may be because of the high tradeoffs small- and mid-sized firms face or due to status quo bias. Our experiment incorporated a vignette that forces decision makers to think about that risk. If the financial pressures of being a small- or medium-sized company operating in a competitive market are such that even trusted advice is ignored, there may be a role for the government to instead increase its resilience investments. With respect to over-investment, some scholars have argued that in some cases in which perceived risks are too high, too many resources may be directed toward disaster preparedness (Mueller 2006). In these industries, regions, or contexts, our results suggest that a firm with a history of unnecessary resilience investment will begin heavily discounting the value of those investments on its own. The influence of agency advice may hasten the reallocation of resources toward more efficient uses. Specifically, decision makers are averse to incurring the opportunity costs of inventories and are more likely to not invest in inventories when their experience with disasters not occurring is congruent with advisory recommendations to not invest in inventories.

\footnotetext{
9 This finding would support the Federal Emergency Management Agency's (FEMA) (2014) recommendation to tailor preparedness messaging by stakeholder and socioeconomic groups.
} 
Trust in expertise and authority and confidence in the effectiveness of protective actions are essential influencers of risk perception (Wachinger, Renn, Begg, and Khulicke 2013). In fact, trust and confidence are second only to personal experience with disasters (Wachinger et al 2013) though the type of risk (i.e., type of disaster) determines the strength of the relationship (Viklund 2003). Perception, along with experience and trust, are the causal mechanisms prompting the pursuit of disaster preparedness measures (Wachinger et al. 2013) or behavioral changes in epidemics (Van Bavel et al. 2020). This has prompted Wachinger et al. (2013) to conclude that, "trust in authorities is necessary to build up a social climate in which advice from authorities will be taken into account in a crisis situation" (p 1061). Historically, government agents communicating risk have not garnered a high degree of trustworthiness, perhaps due to factors inherent in our participatory democracy system (Slovic 1993; Trumbo and McComas 2003).

Our results suggest an additional challenge for authorities and leaders communicating risk and resilience information, namely, differences in how advice with varying content is received. While decision makers in our study overwhelmingly trust advice to invest in resilience, they tend to distrust advice to not invest. This is consistent with the literature describing the asymmetry of trust, or the phenomenon in which distrust is relatively more difficult to overcome due to both the visibility and over-weighting of negative (trust destroying) events (Slovic 1993, 1999). Some distrust is likely prompted by uncertainty. Advice accuracy positively relates to resilience investment for both types of advice (invest and do not invest), but the research subjects tend to trust advice to invest. The practical application, then, is that in situations in which advisors (i.e., government agencies or other economic organizations) seek to combat over-investment in resilience, they should consider the potential that this message will be met with distrust, indifference or disregard. At the same time, LeClerc and Joslyn (2015) found that increasing uncertainty as part of the advice message offered helped to alleviate the risk that false alarms might lead to future advice being discounted. The implication in this context is that when providing information or advice related to investing or not investing in inventories, presenting ranges of probabilities of events or outcomes may increase the trust in that advice. Presenting reliable information in a joint participation exercise may also increase trust between the public, experts, and authorities (Wachinger et al. 2013). In light of this literature and our findings, we propose that when government agencies provide advice against investing in resilience they do so by way of participatory processes.
Funding The funding was provided by the National Center for the Middle Market and the Battelle Center for Science and Technology Policy.

Data availability All of the data and models that support the study findings are available upon request from the corresponding author for purposes of replicating or validating findings. However, during the period in which the results of this suite of experiments are being published in this and other outlets, the data will not be posted to publicly available repositories. Upon completion of the authors' use of the data, the finalized data will be made publicly available and posted online, and requesters' use of the data for subsequent publication and broader dissemination will be permitted.

Code availability Code are available upon request.

\section{Declarations}

Conflict of interest The author declares that they have no conflict of interest.

\section{References}

Alderson DL, Brown GG, Matthew CW (2015) Operational models of infrastructure resilience. Risk Anal 35(4):562-586

Allison P (2015) Don't put lagged dependent variables in mixed models. Retrieved from: https://statisticalhorizons.com/lagged-depen dent-variables

Atkinson SM, Baird SB, Frye MB (2003) Do female mutual fund managers manage differently? J Financ Res 26(1):1-18

Azadegan A, Jayaram J (2018) Resiliency in supply chain systems: a triadic framework using family resilience model. In: Khojasteh Y (ed) Supply chain risk management. Springer, Singapore

Beckmann D, Menkoff L (2008) Will women be women? Analyzing the gender difference among financial experts. Kyklos 61(3):364-384

Bernile G, Bhagwat V, Rau PR (2017) What doesn't kill you will only make you more risk-loving: Early-life disasters and CEO Behavior. J Financ 72(1):167-206

Bell HM, Tobin GA (2007) Efficient and effective? The 100-year flood in the communication and perception of flood risk. Environ Hazards 7(4):302-311

Bhargava A, Sargan JD (1983) Estimating dynamic random effects models from panel data covering short time periods. Econometrica 51(6):1635-1659

Booth AL, Katic PA (2013) Cognitive skills, gender and risk preferences. Econ Record 89(284):19-30

Brusset X, Teller C (2017) Supply chain capabilities, risks, and resilience. Int J Prod Econ 184:59-68

Burns, P (1985) Research in experimental economics. In: Experience and decision making: a comparison of students and businessmen in a simulated progressive auction, Vol. 3. JAI Press, Greenwich, pp 139-153

Cacioppo JT, Reis HT, Zautra AJ (2011) Social resilience: the value of social fitness with an application to the military. Am Psychol 66(1):43-51

Carpenter S, Walker B, Anderies JM, Abel N (2001) From metaphor to measurement: resilience of what to what? Ecosystems 4:765-781

Chang SE, McDaniels T, Fox J, Dhariwal R, Longstaff H (2014) Toward disaster-resilient cities: characterizing resilience of infrastructure systems with expert judgments. Risk Anal 34(3):416-434 
Charness G, Gneezy U (2012) Strong evidence for gender differences in risk taking. J Econ Behav Org 83:50-58

Chowdhury MMH, Quaddus M (2017) Supply chain resilience: conceptualization and scale development using dynamic capability theory. Int J Prod Econ 188:185-204

Cimellarom GP, Reinhorn AM, Bruneau M (2010) Framework for analytical quantification of disaster resilience. Eng Struct 32:3639-3649

Connelly EB, Allen CR, Hatfield K, Palma-Oliveira JM, Woods DD, Linkov I (2017) Features of resilience. Environ Syst Decis 37(1):46-50

Cronqvis H, Makhija AK, Yonker SE (2012) Behavioral consistency in corporate finance: CEO personal and corporate leverage. J Financ Econ 103(1):20-40

Cutter S, Barnes L, Berry M, Burton C, Evans E, Tate E, Webb TJ (2008) A place-based model for understanding community resilience to natural disasters. Global Environ Change 18(4):598-606

Dormady NC, Greenbaum RT, Young KA (2021) Value of information on resilience decision-making in repeated disaster environments. Nat Hazards Rev 22(1):04020048. https://doi.org/10.1061/ (ASCE)NH.1527-6996.0000415

Dormady N, Roa-Henriquez A, Rose A (2019a) Economic resilience of the firm: a production theory approach. Int J Prod Econ 208:446-460

Dormady N, Rose A, Rosoff H, Roa-Henriquez A (2019b) A survey approach to measuring the cost-effectiveness of economic resilience to disasters. In: Ruth M, Reisemann S (eds) Resilience of socio technical systems. Edward Elgar, Cheltenham

Eckel CC, Grossman PJ (2008) Forecasting risk attitudes: an experimental study using actual and forecast gamble choices. J Econ Behav Org 68:1-17

Englander A (2015) Multidimensional ambiguity and individual willingness to take preventive action (Senior Thesis) Department of Economics, The Ohio State University

Federal Emergency Management Agency (2014) Preparedness in America: Research insights to increase individual, organizational, and community action. Updated: August 2014. https://www.fema. gov/media-library-data/1409000888026-1e8abc820153a6c8cde2 4ce42c16e857/20140825_Preparedness_in_America_August_ 2014_Update_508.pdf

Filippin A, Crosetto P (2016) A reconsideration of gender differences in risk attitudes. Manage Sci 62(11):3138-3160

Fréchette GR (2016) Experimental economics across subject populations. In: Kagel JH, Roth AE (eds) The handbook of experimental economics. Princeton University Press, Princeton, pp 435-480

Fréchette GR (2015) Laboratory Experiments: Professionals Versus Students. In: Fréchette GR, Schotter A (eds) Handbook of experimental economic methodology. Oxford University Press, Oxford, pp 360-390

Gerber BJ (2007) Disaster management in the United States: examining key political and policy challenges. Policy Stud J 35(2):227-238

Gunasekara FI, Richardson K, Carter K, Blakely T (2014) Fixed effects analysis of repeated measures data. Int J Epidemiol 43(1):264-269

Hanley JA, Negassa A, Forrester JE (2003) Statistical analysis of correlated data using generalized estimating equations: an orientation. Am J Epidemiol 157(4):364-375

Hynes W, Trump B, Love P, Linkov I (2020) Bouncing forward: a resilience approach to dealing with COVID-19 and future systemic shocks. Environ Syst Decis 40:174-184

He TS, Hong F (2018) Risk breeds risk aversion. Exp Econ 21(4):815-835

Henry D, Ramirez-Marquez E (2016) On the impacts of power outage during Hurricane Sandy-a resilience-based analysis. Syst Eng 19(1):59-75
Hertwig R, Barron G, Weber EU, Erev I (2004) Decisions from experience and the effect of rare events in risky choice. Psychol Sci 15(8):534-539

Holling CS (1973) Resilience and stability of ecological systems. Annu Rev Ecol Syst 4(1):1-23

Hollnagel E, Woods DD, Leveson N (2006) Resilience engineering: concepts and precepts. Ashgate Publishing Ltd, Farnham

Hosseini S, Barker K (2016) A Bayesian network model for resilience-based supplier selection. Int J Prod Econ 180:68-87

Jensen MC, Murphy KJ (1990) Performance pay and top management incentives. J Polit Econ 98(2):225-264

Kagel J, Roth A (eds) (2015) The handbook of experimental economics: Volume 2. Princeton University Press, Princeton

Kagel J, Roth A (eds) (1995) The handbook of experimental economics. Princeton University Press, Princeton

Kahneman D, Tversky A (1979) Prospect theory: an analysis of decision under risk. Econometrica 47(2):263-292

Kamalahmadi M, Parast MM (2016) A review of the literature on the principles of enterprise and supply chain resilience: major findings and directions for future research. Int J Prod Econ 171:116-133

Kerkhoff AJ, Enquist BJ (2007) The implications of scaling approaches for understanding resilience and reorganization in ecosystems. Bioscience 57(6):489-499

Kim H, Marcouiller DW (2015) Considering disaster vulnerability and resiliency: the case of hurricane effects on tourism-based economies. Ann Reg Sci 54:945-971

Kripfganz S (2016) Quasi-maximum likelihood estimation of linear dynamic short-T panel-data models. Stata J 16(4):1013-1038

LeClerc J, Joslyn S (2015) The cry wolf effect and weather-related decision making. Risk Anal 35(3):385-395

Levitt SD, List JA, Reiley DA (2010) What happens in the field stays in the field: exploring whether professionals play minimax in laboratory experiments. Econometrica 78(4):1413-1434

Liang KY, Zeger SL (1986) Longitudinal data analysis using generalized linear models. Biometrika 73:13-22

List JA (2001) Do Explicit warnings eliminate the hypothetical bias in elicitation procedures? Evidence from field auctions for sportscards. Am Econ Rev 91(5):1498-1507

List JA (2002) Preference reversals of a different kind: the "more is less" phenomenon. Am Econ Rev 92(5):1636-1643

List JA, Haigh MS (2005) A Simple test of expected utility theory using professional traders. PNAS 102(3):945-948

Martin RL (2018) Shocking aspects of regional development: Towards an economic geography of resilience. In The new Oxford handbook of economic geography.

Martin R, Sunley P (2014) On the notion of regional economic resilience: conceptualization and explanation. J Econ Geogr 15:1-42

Miles SB, Chang SE (2011) ResilUS: a community based disaster resilience model. Cartogr Geogr Inf Sci 38(1):36-51

Mueller JE (2006) Overblown: how politicians and the terrorism industry inflate national security threats, and why we believe them. Simon and Schuster, New York

Naderpajouh N, David JY, Aldrich DP, Linkov I, Matinheikki J (2018) Engineering meets institutions: an interdisciplinary approach to the management of resilience. Environ Syst Decis 38(3):306-317

Nickell S (1981) Biases in dynamic models with fixed effects. Econometrica 49(6): 1417-1426

Palacios-Huerta I, Volij O (2008) Experientia docet: professionals play minimax in laboratory experiments. Econometrica 76:71-115

Park J, Cho J, Rose A (2011) Modeling a major source of economic resilience to disasters: recapturing lost production. Nat Hazards 58:163-182

Pimm SL (1984) The complexity and stability of ecosystems. Nature 307(5949):321-326 
Plott C, Smith VE (2008) Handbook of experimental economics results, vol 1. North-Holland Press, Amsterdam

Popovich N, O’neill C (2017) A '500-Year Flood' Could Happen Again Sooner Than You Think. Here's Why. The New York Times

Roe BE, Just DR (2009) Internal and external validity in economics research: tradeoffs between experiments, field experiments, natural experiments, and field data. Am J Agric Econ 91(5):1266-1271

Rose AZ (2004) Defining and measuring economic resilience to disasters. Prev Manage 13(4):307-314

Rose AZ (2007) Economic resilience to natural and man-made disasters: multidisciplinary origins and contextual dimensions. Environ Hazards 7(4):383-398

Rose A (2009) A framework for analyzing and estimating the total economic impacts of a terrorist attack and natural disaster. J Homeland Secur Emerg Manage 6(1), Article 6

Rose A (2017) Benefit-cost analysis of economic resilient actions. In S. Cutter (ed.) Oxford research encyclopedia of natural hazard science. Oxford, New York

Rose A, Liao S (2005) Modeling regional economic resilience to disasters: a computable general equilibrium analysis of water service disruptions. J Reg Sci 45(1):75-112

Roth A (1995) Introduction to experimental economics. In: Kagel JH, Roth AE (eds) The handbook of experimental economics. Princeton University Press, Princeton, pp 3-109

Roussanov N, Savor P (2014) Marriage and managers' attitudes to risk. Manage Sci 60(10):2496-2508

Schubert R, Brown M, Gysler M, Brachinger HW (1999) Financial decision-making: are women really more risk-averse? Am Econ Rev 89(2):381-385

Shafieezadeh A, Burden LI (2014) Scenario-based resilience assessment framework for critical infrastructure systems: case study for seismic resilience of seaports. Reliab Eng Syst Saf 132:207-219

Sila V, Gonzales A, Hagendorff J (2016) Women on board: does boardroom gender diversity affect firm risk? J Corp Financ 36:26-53

Slovic P (1993) Perceived risk, trust, and democracy. Risk Anal 13(6):675-682

Slovic P (1999) Trust, emotion, sex, politics, and science: Surveying the risk-assessment battlefield. Risk Anal 19(4):689-701

Sonfield M, Lussier R, Corman J, McKinney M (2001) Gender comparisons in strategic decision-making: an empirical analysis of the entrepreneurial strategy matrix. J Small Business Manage 39(2): $165-173$

Tang C, Tomlin B (2008) The power of flexibility for mitigating supply chain risks. Int J Prod Econ 116:12-27

Tierney K (2006) Businesses and disasters: vulnerability, impacts, and recovery. In: Rodriguez H, Quarantelli EL, Dynes RR (eds) Handbook of disaster research. Springer, New York, pp 275-296

Tierney K (2019) Disasters: A Sociological Approach. Polity, Cambridge

Trumbo CW, McComas KA (2003) The function of credibility in information process for risk perception. Risk Anal 23(2):343-353

Tversky A, Kahneman D (1971) Belief in the law of small numbers. Psychol Bull 76(2):105-110

Van Bavel JJ, Baicker K, Boggio PS, Capraro V, Cichocka A, Cikara $M$ et al (2020) Using social and behavioural science to support COVID-19 pandemic response. Nat Hum Behav 4:460-471

Viklund MJ (2003) Trust and risk perception in Western Europe: a cross-national study. Risk Anal 23(4):727-738

Vugrin ED, Warren DE, Ehlen MA (2011) A resilience assessment framework for infrastructure and economic systems: quantitative and qualitative resilience analysis of petrochemical supply chain to a Hurricane. Process Saf Progress 30(3):280-290

Yechiam E, Barron G, Erev I (2005) The role of personal experience in contributing to different patterns of response to rare terrorist attacks. J Conflict Resolut 49(3):430-439

Youn BD, Hu C, Wang P (2011) Resilience-driven system design of complex engineered systems. J Mech Des 133(10):101011

Young KA, Greenbaum RT, Dormady NC (2017) Sex, gender, and disasters: experimental evidence on the decision to invest in resilience. Int J Disaster Risk Reduct 24:430-450

Wachinger G, Renn O, Begg C, Kuhlicke C (2013) The risk perception paradox-implications for governance and communication of natural hazards. Risk Anal 33(6):1049-1065

Webb CT (2007) What is the role of ecology in understanding ecosystem resilience? Bioscience 57(6):470-471

White RK, Edwards WC, Farrar A, Plodinec MJ (2014) A practical approach to building resilience in America's communities. Am Behav Sci 59(2):200-219

Zeger SL, Liang KY, Albert PS (1988) Models for longitudinal data: a generalized estimating equation approach. Biometrics 44:1049-1060 